\title{
Neural control of swallowing
}

\author{
Milton Melciades Barbosa COSTA
}

Received 11/4/2018

Accepted $9 / 5 / 2018$

\begin{abstract}
Background - Swallowing is a motor process with several discordances and a very difficult neurophysiological study. Maybe that is the reason for the scarcity of papers about it. Objective - It is to describe the chewing neural control and oral bolus qualification. A review the cranial nerves involved with swallowing and their relationship with the brainstem, cerebellum, base nuclei and cortex was made. Methods - From the reviewed literature including personal researches and new observations, a consistent and necessary revision of concepts was made, not rarely conflicting. Results and Conclusion - Five different possibilities of the swallowing oral phase are described: nutritional voluntary, primary cortical, semiautomatic, subsequent gulps, and spontaneous. In relation to the neural control of the swallowing pharyngeal phase, the stimulus that triggers the pharyngeal phase is not the pharyngeal contact produced by the bolus passage, but the pharyngeal pressure distension, with or without contents. In nutritional swallowing, food and pressure are transferred, but in the primary cortical oral phase, only pressure is transferred, and the pharyngeal response is similar. The pharyngeal phase incorporates, as its functional part, the oral phase dynamics already in course. The pharyngeal phase starts by action of the pharyngeal plexus, composed of the glossopharyngeal (IX), vagus (X) and accessory (XI) nerves, with involvement of the trigeminal (V), facial (VII), glossopharyngeal (IX) and the hypoglossal (XII) nerves. The cervical plexus (C1, C2) and the hypoglossal nerve on each side form the ansa cervicalis, from where a pathway of cervical origin goes to the geniohyoid muscle, which acts in the elevation of the hyoid-laryngeal complex. We also appraise the neural control of the swallowing esophageal phase. Besides other hypotheses, we consider that it is possible that the longitudinal and circular muscular layers of the esophagus display, respectively, long-pitch and short-pitch spiral fibers. This morphology, associated with the concept of energy preservation, allows us to admit that the contraction of the longitudinal layer, by having a long-pitch spiral arrangement, would be able to widen the esophagus, diminishing the resistance to the flow, probably also by opening of the gastroesophageal transition. In this way, the circular layer, with its short-pitch spiral fibers, would propel the food downwards by sequential contraction.
\end{abstract}

HEADINGS - Deglutition. Cranial nerves. Brain stem. Basal ganglia. Cerebral cortex. Neural pathways.

\section{INTRODUCTION}

To understand how the nervous system controls any biological process, we must know what are the necessary afferent and efferent impulses, where they came from, what is their destination and which functions integrate this process ${ }^{(1)}$. Swallowing is a motor process with a very difficult neurophysiological study, and subject of several discordances ${ }^{(2)}$. These observations and the literature review show that great part of the accepted mechanisms for the neural control of swallowing could not be considered trustworthy hypotheses. In this way, the neural control of swallowing remains as a research field, open to new considerations.

The swallowing process is formed by the oral, pharyngeal and esophageal phases ${ }^{(2,3)}$, with much controversy involving their mechanisms. Great evolution has been obtained with observations of neurological lesions and many are the methods available for confirmation of the hypotheses that, in the end, remain as just hypotheses. Nevertheless, there is an expressive quantity of new morphological and functional conceptions that, even being only hypotheses, at least are more structured than the empirical others used until now to explain the swallowing mechanisms.

It had been believed that the swallowing control center was located exclusively in the brainstem, and that the entire swallowing mechanism, automatic and semiautomatic movements of chewing and swallowing, were involuntary by genesis and regulation. From observations of patients with cortical dysphagia, the role of the cerebral cortex in the swallowing control mechanism has been recognized and extensively studied ${ }^{(4)}$.

Based on the nervous system embryology a rhombencephalic center, formed by association of the third primitive vesicle (hindbrain) with the second one (mesencephalon or midbrain), origin of the brainstem and cerebellum was described. The rhombencephalic center would receive stimuli produced by the food bolus passage over existing receptors at the base of the tongue, on the palatoglossal and palatopharyngeal pillars, on the palate, and pharyngeal walls, especially in the posterior one, starting an involuntary and coordinated process that would characterize the pharyngeal phase of swallowing. The assumption was that this phase would be controlled, in physiological circumstances, by a framework continuously modified by peripheral afferent stimuli that would especially influence the muscular function, adjusting strength and time of contraction to the size of bolus swallowed. The bolus entrance in the oropharynx would produce soft palate elevation and reflex contraction of the upper pharynx constrictor. In addition, to protect the airways, the bolus entrance would initiate a peristaltic wave that would propagate to the other muscles, narrowing the pharynx, except at the level of the cricopharyngeal muscle, which would relax, allowing the passage of the pharyngeal content to the esophagus ${ }^{(5)}$.

\footnotetext{
Declared conflict of interest of all authors: none

Disclosure of funding: no funding received

Universidade Federal do Rio de Janeiro (UFRJ), Centro de Ciências da Saúde, Instituto de Ciências Biomédicas, RJ, Brasil.

Corresponding author: Milton Costa. Orcid: 0000-0003-0245-6020. E-mail: mcosta@acd.ufrj.br
} 
A center involving sensory and motor nuclei integrated by a network of interneurons located in the brainstem complements the described coordination ${ }^{(6,7,8)}$.

A new approach considers the oropharynx functional activity as composed by the oral and pharyngeal phases of swallowing ${ }^{(2,9,10)}$. This functional activity would be produced by muscular contraction, and coordinated by a control center in the brainstem, designated as the Central Pattern Generator (CPG) for Swallowing ${ }^{(9,11-15)}$.

This pattern-generating center would consist of two hemicenters, one on each side of the brainstem, which, under physiological conditions, would synchronize and organize the bilateral contraction of the oral and pharyngeal muscles. Their nerve fibers would cross the midline of the brainstem, interconnecting the two halves of the involved generating centers with swallowing-linked neurons in the dorsal and ventral regions of the brainstem ${ }^{(16,17)}$.

It has been admitted that in this pattern-generating center the solitary tract nucleus would receive information that would converge to it both from peripheral impulses triggered by the swallowing stimulus and from the cerebral cortex ${ }^{(9,18)}$. This convergence of stimuli to the solitary tract nucleus would be primarily important for the induction of voluntary swallowing ${ }^{(15)}$. It's been considered that the first event observed in the "swallowing reflex" would occur in the oropharyngeal cavity (oral and pharyngeal cavities), where the bolus would produce a sensory afferent stimulus that would inform the brainstem and cortex ${ }^{(19-21)}$.

In nutritive swallowing, the first cortical command would be sent to the solitary tract nucleus. Thus, eating and drinking sequentially could be voluntarily initiated or facilitated by the cerebral cortex through the neural network (CPG) of the brainstem ${ }^{(2,20,22,23)}$. It was also considered that, in voluntary deglutition, regions of the cortex and subcortical areas related to swallowing would serve mainly to trigger and control the onset of the swallowing motor sequence, especially the oral phase ${ }^{(20)}$.

In disagreement with the bilateral integration of the brainstem, admitted in the pattern-generating center conception ${ }^{(9,11-15)}$, it has already been described that both the dorsal (sensory) and ventral (motor) regions represented on both sides of the brainstem would be able to independently coordinate the pharyngeal and esophageal phases of swallowing on each side ${ }^{(24)}$.

Although the oral and pharyngeal cavities are morphologically contiguous and have sequential function, the oral and pharyngeal swallowing phases are distinct from each other in structures, innervation and neural control. The oral phase is voluntary and the pharyngeal one is reflex. Designating the oral and pharyngeal phases as oropharyngeal or buccopharyngeal ${ }^{(2,9,10,12,25,26)}$ is inadequate, although not rare. Anatomically, the oropharynx is the intermediate segment that communicates the oral and pharyngeal cavities, receiving the contents transferred during swallowing, which in no way defines the functional role of the oral and pharyngeal phases of swallowing.

High dysphagia has been often defined as oropharyngeal dysphagia. High dysphagia may occur with impairment of both phases, but the possibility of exclusively oral or pharyngeal injury cannot be ignored. The fact that the injury of one neighboring phase interferes with the dynamics of the other emphasizes commitment of the sequence, and not of both phases. The oropharyngeal designation for this kind of dysphagia diverts the clinical and therapeutic focuses, which should be directed to the actually compromised phase, with doubtful therapeutic adequacy. The designation of oropharyngeal dysphagia led us to misclassify the dysphagia that affects the oral and pharyngeal phases as transference dysphagia, and the esophageal dysphagia, as a conduction one. Transference is proper to the oral phase, and conduction, to the pharyngeal and esophageal phases. Transference is a voluntary process and occurs in the voluntary oral phase, and conduction occurs in the pharyngeal and esophageal phases, both reflex ${ }^{(27)}$.

It is a fact that we have learned very much by observing neurological dysphagia. In addition, today there are many methods available for study of swallowing and its disorders, which, while enabling us to better understand the swallowing physiology, highlight the significant number of conflicting concepts still in force.

The aim of this work is to offer new conceptual alternatives, based on the literature and personal research, to give a more solid basis to the hypotheses used to explain the swallowing mechanisms and, consequently, the neural control of swallowing.

\section{CHEWING}

Mastication, basically voluntary, integrates the activation of the chewing muscles, innervated by the trigeminal pair $(\mathrm{V})$, the tongue muscles, innervated by the hypoglossal pair (XII), and with less evident participation, of the expression muscles, in special the orbicular of the lips and buccinators, which, like other skin-inserted muscles, are innervated by the facial pair (VII). Trigeminal afferent fibers reach the dorsal region of the brainstem (the main sensory nucleus of the V) and, still in an afferent pathway through the trigeminal lemniscus, reach the thalamus, from where axons go to the postcentral gyrus (somatosensory cortex) in the parietal region of the cerebral cortex ${ }^{(1)}$. The postcentral gyrus transfers information to the precentral gyrus (somatomotor cortex) in the frontal region, generating a motor efferent response by the nuclear cortical route (pyramidal-voluntary), which reaches the ventral region of the brainstem, where on each side the trigeminal motor nucleus is located. From this nucleus, the motor route of the trigeminal nerve activates the chewing muscles ${ }^{(1,28-31)}$.

By activation from the cortex-nuclear pathway, the hypoglossal motor nucleus in the brainstem gives dynamics to the tongue in its participation in the chewing process. Afferent and efferent facial nerve pathways, in functional association, participate in the accommodation of the bolus and in the oral cavity pressure by adjusting the tension of the cavity walls, especially dependent on the orbicularis of the lips and buccinators.

The afferent trigeminal fibers also reach its mesencephalic nucleus, which connects its sensory route with its motor root in absence of cortical relation. This direct, sensory-motor relationship allows the chewing action, which is voluntary, to have a reflex component ${ }^{(1)}$, which, by proprioceptive perception during the preparation of the bolus, modulates the variation of the chewing intensity produced by the continuous modification of the resistance of the bolus under preparation.

\section{ORAL QUALIFICATION}

The oral cavity is able to identify several characteristics of the inner bolus. It presents at least four distinct types of perception, thermal, painful, mechanical and chemical ${ }^{(32,33)}$.

The thermal-reception can perceive hot or cold in various levels. When pleasing and adequate with the type of food, they can be incorporated to the pleasure of the diet. When extreme and damaging, they produce rejection. 
The pain-reception is usually due to mechanical, thermal or chemical hyper-stimuli produced on sensitive afferent pathways, warning and preventing injury. However, there is a painful submodality produced by capsaicin, present in a large number of peppers, probably using the same pain way, whose perception is often perceived as dietary pleasure.

The mechanical-reception allows noticing the contact of the bolus against the intraoral structures. The tongue that presses the bolus, gathering information defined as tactile. This information allows perceiving the physical characteristics of the bolus, detecting if there is impropriety in its contents. Mechanical-reception is also responsible for the characterization of oral bolus volume and viscosity, to define how much motor units must be depolarized for the necessary generation of oral pressure to transfer the contents from the oral cavity to the pharynx.

The chemical-reception identifies the tastes by different mechanisms. Sweet appears to be identified by coupling of a primary messenger (taste protein) with a secondary messenger (cAMP - cyclic adenosine monophosphate), whose concentration increase closes the potassium channels in the gustatory receptors, with membrane depolarization. It is considered that the intracellular metabolic pathways responsible for natural sweeteners would be distinct from those activated by artificial sweeteners, whose secondary messenger would be the IP3 (inositol triphosphate), which would act on the calcium channels, provoking calcium input into the cells, with depolarization. The identification of the bitter taste is given by coupling of the same primary messenger (taste protein), resulting in calcium increase due to action of the IP3 secondary messenger, releasing a neurotransmitter without membrane depolarization. The salty perception is generated by direct passage of sodium through the membrane channels that depolarize. The hydrogen from sour or acid penetrates the cellular membrane by blocking the potassium channels, which supports the membrane depolarization ${ }^{(32,33)}$.

Although sweet, salty, sour and bitter are the tastes considered basic, others like metallic, astringent and more recently, umami (monosodium glutamate) have been suggested as primary. Nevertheless, the first four were the ones that resisted as basic over time. It is not very clear whether and how the association of basic tastes (sweet, salty, sour and bitter) can appropriately produce the palate, i.e. the gustatory perception as a whole. The palate, which can distinct for each of us, is an association of the social level and learning, basic tastes, tactile and thermal perceptions, and certainly the impressions permitted by the vision and smell senses ${ }^{(33,34)}$

The perception of tastes in the oral cavity has been prioritized on the tongue. Classic description points to sequential areas on each side of the anterior $2 / 3$ of the tongue as having selective capacity for the basic tastes, the anterior tip to sweet, the sides, in sequence to salty and sour, and the posterior central area, to bitter ${ }^{(31,34-39)}$. This concept, already contested, shows that the tongue is able to perceive all the basic tastes in all its regions, with expressive predominance of the bitter one ${ }^{(40-42)}$.

The tongue's filiform, fungiform, foliate and circumvallate papillae are anatomical elements involved with the chemical senses (taste). These papillae display incrusted gustatory buttons. In the filiform papillae, gustatory buttons are rare or absent. In the fungiform ones there are few, but in the foliate papillae and especially in circumvallate ones, there are many gustatory buttons ${ }^{(41,42)}$.

Buttons considered as gustatory can be identified, in addition to the tongue papillae, on the palate and vallecula. Buttons with similar morphology to those defined as gustatory have been found on the pharynx regions, where, at first, no taste is perceived. In the vallecula, even with the oral cavity anesthetized, the bitter taste transferred to the pharynx can be perceived by vagus nerve conduction $^{(41)}$.

As far as we know, in the oral cavity there have not been described or observed any other morphological kind of receptors than that admitted as gustatory. However, the oral cavity holds several other perceptions. Specific receptors to be stimulated are supposedly necessary. Nevertheless, there is no evidence indicating that any receptor is responsible for detecting only one type of stimulus ${ }^{(43)}$.

It is possible that receptors deemed gustative are also able to receive other oral stimuli. This hypothesis is reinforced by the presence of receptors morphologically similar to the gustatory receptor, where tastes are not perceived as palate, in the pharynx (except the in vallecula) and laryn $x^{(34)}$. There are also gustatory perception descriptions by thermal stimulation of the tongue ${ }^{(44)}$, such as sweet perception by heating the anterior edge of the tongue from a cool state, and evocation of acid or salty perception with cooling intensification ${ }^{(45)}$.

\section{CRANIAL NERVES}

The cranial nerves associated with the swallowing process are the trigeminal (V), facial (VII), glossopharyngeal (IX), vagus (X), accessory (XI) - usually not considered - and hypoglossal (XII). It should be emphasized that the structures involved in the swallowing process are pairs, both anatomically and/or functionally, due to the dual-side innervation. Anatomically unique, the tongue, palate, pharynx and larynx are functional pairs, each side having independent innervation ${ }^{(1,7,29,30)}$.

From receptors on each side of the oral cavity, the trigeminal (V), facial (VII) and glossopharyngeal (IX) nerves conduct information to the brainstem. These mixed nerves lead sensitivity (afferent pathway) and motor command (efferent pathway). The afferent pathways of the anterior two thirds of the tongue are supplied by the lingual nerve, which associates the trigeminal (general sensibility) with the facial nerve (taste). In the posterior third of the tongue, both the general sensibility and taste are conducted by the glossopharyngeal nerve ${ }^{(33,39,41-46)}$.

In its afferent pathways toward the brainstem, the trigeminal, facial and glossopharyngeal nerves of both sides will make ganglionar synapses similar to the posterior roots of the spinal cord. The afferent pathway of the trigeminal nerve makes synapses in the trigeminal ganglion (Gasser), the facial nerve, in the geniculate ganglion, and the glossopharyngeal, in the rostral ganglion (upper one $)^{(1,30,39)}$.

The trigeminal nerve (V) has three branches; upper (ophthalmic), middle (maxillary) and lower (mandibular). The upper and medium are exclusively sensitive, and the inferior, mixed. The sensitive fibers of the three branches innervate the face in transverse bands of representation. Regarding the oral cavity, the middle branch (maxillary) has sensitive responsibility for the upper arcade teeth, upper lip, cheeks, hard palate (mouth mucosa) and mucosa of the rhinopharynx. The sensitive portion of the lower branch (mandibular) is responsible for the sensitivity of the lower arcade teeth and lower mucosa of the mouth, as well as by the general sensitivity of the anterior $2 / 3$ of the tongue ${ }^{(1,29,30)}$.

From the trigeminal ganglion to the brainstem, all the sensory pathways will end in the posterior portion of the brainstem, over the trigeminal sensitive nucleus that occupies the medulla oblongata 
(spinal tract nucleus of the cranial nerve V), the pons (main sensory nucleus of the cranial nerve $\mathrm{V}$ ) and the midbrain (midbrain nucleus of the cranial nerve V). Centrally the sensitive fibers divide into short, ascending branches that end in the main sensorial nucleus, to attend to tactile sensibility, and into long, descending branches that serve to tact, temperature and pain, also providing collateral pathways to the spinal nucleus of the cranial nerve $\mathrm{V}^{(29)}$.

It is believed that proprioceptive fibers from the midbrain nucleus of the trigeminal neve, in synapse with its motor nucleus located in the upper portion of the pons ${ }^{(47)}$, would be able to integrate important chewing reflex $\operatorname{arcs}^{(1,29)}$. Unless expressly desired, these arcs allow reflex modulation of chewing intensity based on bolus consistency variations, even during the voluntary bolus chewing preparation.

The motor root of the trigeminal nerve emerges from the ventral portion of the pons and runs through the mandibular root to innervate the chewing muscles, the mylohyoid, the anterior belly of the digastric and the tensor muscle of the palate $e^{(1,29,30)}$.

The facial nerve (VII) is a mixed one, considering its motor root in association with the sensitive root given by the intermediate (Wrisberg) nerve ${ }^{(1)}$. The taste of the anterior two thirds of the tongue on each side are its responsibility. From the tongue, this afferent, pre-ganglionic route follows through the lingual nerve (association of nerves V and VII), and afterwards through the tympanic cord nerve (facial branch), to make synapses on the geniculate ganglion. Through the intermediate nerve, the postganglionic fibers (afferent visceral special - gustative route) synapse in the solitary tract nucleus of the medulla oblongata, associated with the general afferent visceral fibers, providing sensitive innervation to the mucosa of the nasal cavities and soft palate ${ }^{(1)}$.

The parasympathetic efferent fibers of the facial nerve, originating from the upper salivary nucleus located on each side of the upper portion of the medulla oblongata, run through the intermediate nerve and afterwards through the tympanic cord nerve to make synapses in the submandibular ganglion. Thence, through postganglionic fibers, they stimulate salivary secretion of the submandibular and sublingual glands ${ }^{(1)}$.

The motor portion of the facial nerve has its nucleus on the ventral portion of the pons. Its fibers stimulate the skin-inserted muscles in the face, neck and scalp, as well as the posterior belly of digastric and stylohyoid muscles ${ }^{(1,8,29,39)}$.

The glossopharyngeal (IX) nerve comes out of the skull together with the vagus (X) and accessory (XI) nerves. The visceral general afferent and the visceral special afferent fibers of the glossopharyngeal nerve are associated. The visceral general afferent fibers are responsible for the general sensitivity of the oropharynx mucosa and the posterior third of the tongue, and the special visceral afferent fibers, for the taste of the posterior third of the tongue. These preganglionic fibers make synapses with the upper ganglion. The postganglionic fibers will end at the solitary tract nucleus ${ }^{(1,8,29)}$.

The glossopharyngeal nerve's efferent pathways come from two distinct nuclei of the medulla oblongata, the salivary inferior (parasympathetic) nucleus and ambiguous motor (special visceral efferent) nucleus. The parasympathetic fibers stimulate the salivary secretion after synapses with the optic ganglion, from which postganglionic fibers emerge to innervate the parotid gland ${ }^{(1,29,31)}$.

The glossopharyngeal nerve's only motor role is with the stylopharyngeus muscle. Nevertheless, it has already been considered as motor to the superior pharyngeal constrictor muscle, whose activity had been previously attributed to the vagus nerve, responsible for the motor innervation of all pharyngeal constrictors muscles ${ }^{(1,29)}$.

The vagus $(\mathrm{X})$ nerve has relationships extending from the cervical region to the abdomen (transverse colon). Its sensory afference (sensory pathway) connects with the solitary tract nucleus located in the medulla oblongata. The visceral special efference (motor pathway) comes from the ambiguous nucleus in the ventral region of the medulla oblongata, and the parasympathetic fibers (visceral general efference), from the dorsal motor nucleus of the vagus ${ }^{(1,29-31)}$.

The visceral special afferent (taste) and visceral general afferent (sensibility) pathways of the vagus nerve, after synapses in a peripheral ganglion (lower or caudal), have their postganglionic fibers end at the solitary tract nucleus, similar to that observed in the intermediate portion of the facial nerve and in the glossopharyngeal one. The visceral general afferent fibers conduct impulses related to the sensitivity of the pharynx, larynx, trachea and esophagus, and the visceral special afferent route lead taste stimuli from receptors on the vallecula and from a small posterior area of the tongue next to the vallecula ${ }^{(1)}$.

The visceral general efferent (parasympathetic) fibers of the vagus nerve originate in the vagus dorsal motor nucleus, and from it, on each side, they gather in a single-trunk, descending pathway, emitting branches in the cervical, thoracic and abdominal region, where they end. These preganglionic fibers will establish synapses in peripheral ganglia of the parasympathetic vegetative or autonomous nervous system, close to, or even inside, the viscera walls ${ }^{(1,29-31)}$.

The visceral special efferent (motor) fibers of the vagus originate in the ambiguous nucleus, and are responsible for innervation of the striated muscles of the pharynx, larynx and esophagus ${ }^{(1)}$.

The accessory (XI) nerve, not always considered among those related to swallowing control, presents special visceral efferent fibers coming from the ambiguous nucleus (motor to striated muscles of branchial origin) that would join this type of special visceral efferent fibers of the vagus. Thus, in addition to the vagus (X) nerve, the accessory (XI) one would also be responsible for the motor innervation of the striated portions of the pharynx, larynx and esophagus. A possible second association between the vagus and accessory nerves would be the presence of parasympathetic fibers (general visceral efferent) in the accessory nerve, with origin in the dorsal nucleus of the vagus, which would accompany the vagus nerve fibers ${ }^{(1,29,47)}$.

The Hypoglossal (XII) nerve, a motor one, has an individualized nucleus on the ventral-medial portion on each side of the medulla oblongata. It is responsible for the tongue extrinsic and intrinsic muscles. In addition, fibers from the cervical plexus in association with the hypoglossal nerve form the ansa cervicalis, from which a branch from the cervical plexus, usually $\mathrm{C} 1$, will innervate the geniohyoid muscle, one of the responsible for the hyoid-laryngeal displacement ${ }^{(1,8,29)}$.

The pharyngeal plexus (glossopharyngeal, vagus and accessory though vagus) is considered responsible for the pharyngeal reflex phase, where afferent information from the pharynx reach the brainstem, generating efferent stimuli to the pharyngeal structures involved in this phase of the swallowing process.

The pressure transfer from the oral cavity to the pharynx by distention would produce afferent stimuli that would reach the brainstem, in special the sensitive (solitary tract) nucleus. From the sensitive nucleus, through interneurons of the reticular formation, the ventral motor (ambiguous) nucleus of the brainstem generates efferent motor stimuli to the pharyngeal structures. Several structural movements initiated during the voluntary oral phase, 
remain in progress until the end of the pharyngeal phase, such as hyoid-laryngeal elevation, swallowing apnea and tongue posterior projection, to pharynx, started during the oral ejection, without considering the palate tension produced by the trigeminal nerve. In this way, several elements of the oral phase incorporated by the pharyngeal reflex phase allow us to consider the pharyngeal phase as dependent on the cranial nerves V, VII, IX, X, XI and XII of both sides.

\section{BRAINSTEM, CEREBELLUM, BASE NUCLEI AND CORTEX}

The brainstem is formed by the medulla oblongata, the pons and the midbrain. It contains the cranial nerves' nuclei related to swallowing. The sensory nuclei are posteriorly located on both sides, and the motor ones, anteriorly. Interneurons and pathways of the reticular formation interconnect the sensory and motor nuclei in the brainstem. These are also connected with peripheral receptors, cerebellum, and sensory and motor areas of the cerebral cortex through base nuclei, and with peripheral effectors like muscles and salivary glands $\mathrm{s}^{(1,8,28-30,39)}$.

The brainstem receives and emits pathways with stimuli information to be integrated and distributed. From peripheral receptors, the brainstem sensitive nuclei will receive peripheral sensitivity information by general afferent pathways (V, VII, IX), and taste, by special afferent ones (VII, IX, X). During the oral phase, all the bolus characteristics are identified and analyzed by the cortex, which informs the brainstem the pattern to be employed by the oral effectors. The brainstem, through the motor hypoglossal (XII) nerve, will stimulate intrinsic and extrinsic tongue muscles. The other swallowing muscles, as well as those involved in the pharyngeal phase, will be stimulated by motor fibers of visceral special efferent nerves (V, VII, IX, X and XI). The brainstem also depolarizes visceral general efferent parasympathetic pathways to salivary glands (nerves VII and IX) ${ }^{(8,29,30)}$. The vagus $(\mathrm{X})$, and maybe the accessory (XI), send preganglionic parasympathetic fibers to the autonomic digestive system, through fibers from the vagus dorsal nucleus ${ }^{(1,29,47)}$.

In the brainstem, swallowing cranial nerves' pathways make functional connections with the cerebellum. The swallowing cranial nerves go in and out of the cerebellum through the inferior, middle and superior cerebellar peduncles. The inferior one receives mainly afferent signals, the medium, only afferent signals, and the superior, mostly efferent signals. Specific longitudinal pathways interconnect brainstem and cerebellum nuclei with base nuclei and cerebral cortex. In this way, the cerebellum and cerebral cortex can interfere with the mechanics to be effected by the cranial nerves' pathways in the swallowing process ${ }^{(1,8,29)}$.

In addition to balance and muscle tone, the cerebellum acts by determining the temporal sequence of the synergistic contraction of the different skeletal striated muscles, which can generate delay of the motor signals by fractions of a second. It also acts by sequencing the motor activities from one movement to another, and can control the relation of agonist and antagonist muscles. When necessary, the cerebellum also can make adjustments in the motor activities produced by other parts of the brain ${ }^{(1,8,29)}$.

Ascending and descending cerebellar pathways connect the cortex and the cerebellum. Originated in large parts of the premotor and motor cortex, the so-called cortex-pons-cerebellar pathway follows to nuclei in the pons and thence to the contralateral hemisphere of the cerebellum. The signs that enter the cerebellum connect with its nuclei and go out to send signals that are distributed to other parts of the brain. The cerebellar pathway, whose role is to help coordinate the motor activity sequences initiated by the cerebral cortex, originates in the cerebellar cortex and, after connection with one of its main nuclei (dentate), goes to the thalamus and will end in the cerebral cortex ${ }^{(8)}$. Swallowing has its motor control bilaterally represented in the cerebral cortex ${ }^{(48-51)}$. This bilateral representation means that peripheral stimuli reach both cerebral hemispheres, with admitted dominance of one of them. This dominance assumes that, in physiological conditions, the dominant hemisphere inhibits the function of the contralateral one. In dysphagia due to involvement of the dominant hemisphere, it has been observed that the contralateral hemisphere can increase its representation, with apparent functional recovery ${ }^{(52-54)}$.

The oral phase, being voluntary, allows us to decide whether to swallow the oral content. The cortical area with the oral control capacity has been identified in the lower portion of the precentral gyrus (frontal cortex) and postcentral gyrus (parietal cortex), where sensitivity (somatosensory cortex) and motor control (somatomotor cortex) are separated by the central sulcus ${ }^{(55,56)}$. (FIGURE 1).

The intraoral qualification, linked to sensory pathways of the

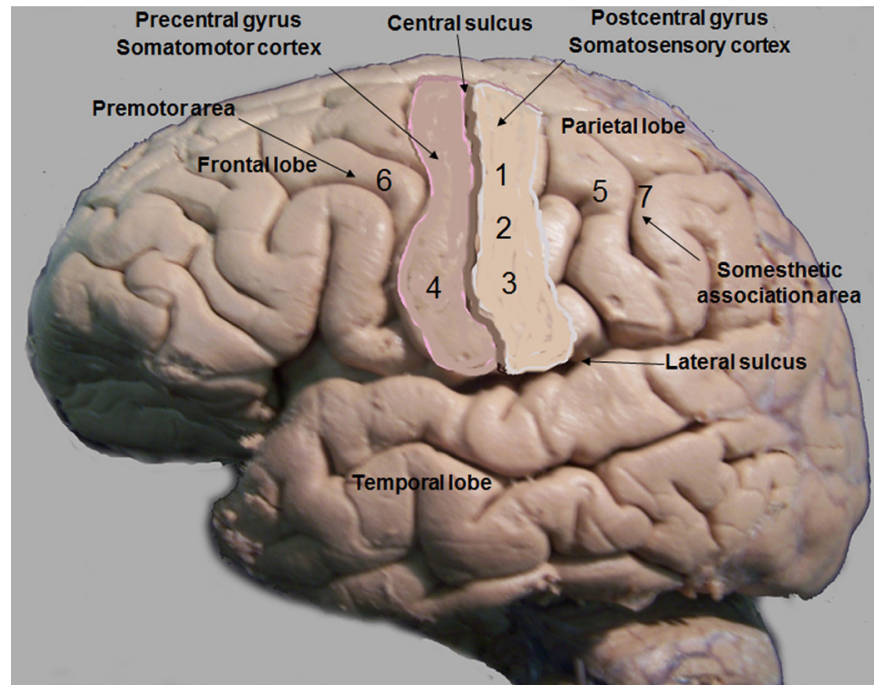

FIGURE 1. Lateral view of an anatomical specimen (brain), highlighting the sensory, postcentral and the motor, precentral gyrus, separated by the central sulcus. The main anatomical elements are described over the figure. 1, 2 and 3: areas of somatosensory cortex; 5 and 7: sensitive association areas; 4: motor cortex; and 6: premotor area.

cranial pairs V, VII and IX, with nuclei in the brainstem, will have visceral afferent general and special stimuli conducted thought base nuclei up to the cerebral cortex. From the cortex, efferent direct or indirect commands (involving the base nuclei) reach the motor nuclei of the brainstem, under cerebellar mediation, from where the motor pathways of these nerve pairs coordinate the dynamics of the peripheral effectors ${ }^{(1,8,29,30)}$.

Afferent pathways of nerves V, VII and IX go to the cerebral cortex. From the trigeminal (V) sensory nucleus, tactile sensitivity pathways pass to the thalamus and cortex trough secondary dorsal tracts. From the spinal nucleus of the cranial pair V, tactile, pain and temperature pathways go to thalamus and cortex via the secondary ventral tract. The facial (VII) and glossopharyngeal (IX) nerves connect with the cerebral cortex through sensitive fibers coming from the solitary tract nucleus through medial lemniscus and 
thalamus. The efferent pathways from the cortex to the brainstem motor nuclei of these three pairs of cranial nerves, modulated by the cerebellum, occur with bilateral (mainly cross) connections of the cortex-nuclear tract (voluntary). These voluntary pathways will end in the brainstem in connection with the motor nucleus of the nerves V and VII, as well as with motor neurons of the pair IX in the ambiguous nucleus ${ }^{(28,29)}$.

\section{ORAL PHASE OF SWALLOWING}

The oral phase can be classified into five subtypes: 1) Nutritional voluntary oral phase; 2) Primary cortical voluntary oral phase; 3) Semi-automatic oral phase; 4) Subsequent gulps oral phase; and 5) Spontaneous oral phase. These five oral phase possibilities occur in association with pharyngeal and esophageal reflex phases.

\section{Nutritional voluntary oral phase}

The nutritive swallowing following chewing, with the bolus prepared and qualified, will put it usually over the tongue (organize) and transfer it (eject) to the pharyn $x^{(57)}$. The voluntary oral phase of swallowing leads information to the cortex by the afferent pathways of the nerves V, VII and IX (mixed pairs) that allow the cortex to activate the motor portions of these mixed nerves in association with the hypoglossal (XII - motor pair). Originating in peripheral receptors, afferent pathways reach the brainstem. From the sensory nuclei of the cranial pair $\mathrm{V}$, through the secondary ventral and dorsal tracts, they reach the thalamus and cortex with tactile (also volume and viscosity), thermal and possibly nociceptive sensations. Afferent general (sensitivity) and special (taste) pathways led by the cranial nerves VII and IX reach the solitary tract nucleus in the dorsal region of the medulla oblongata. From this, afferent pathways connect with the base nuclei, including thalamus, and then with the cerebral cortex on the postcentral gyrus of both hemispheres, transferring the received afferent signals to the precentral gyrus, from where efferent pathways go to the brainstem motors nuclei (V, VII, IX, XII).

Based on the hemisphere dominance, one can conclude that both afferent general (sensitive) and special (taste), and efferent special (motors) and general (parasympathetic) pathways interconnecting both sides of cortex and brainstem arrive and leave as direct and cross paths. This organization gives to each cerebral hemisphere the total information collected in the oral cavity, enabling effective commands from each hemisphere to reach both sides of the brainstem, integrating the cranial nerves that act in the oral phase ${ }^{(58)}$.

After activating the sensorial cortex on both sides from the base nuclei, the peripheral information passes to the motor cortex, where the necessary intensity is modulated and re-transmitted to the base nuclei and brainstem. In the latter, the efferent pathways of the trigeminal, facial and hypoglossal nerves would produce an oral dynamic that would end by ejecting its contents into the pharynx.

Although one of the hemispheres is dominant, both are fully informed, allowing them to exercise full functions ${ }^{(48-51)}$. There is evidence that the dysphagia generated by injury to the dominant hemisphere allows increase in the representation of the non-dominant (non-injured) hemisphere, associated with apparent function recovery ${ }^{(52-54)}$. There are pathways crossing from one side to the other through the corpus callosum, integrating the hemispheres. Thus, in healthy individuals, the dominant cortex can exert inhibitory action on the contralateral one by a connection that passes through the corpus callosum. It is also possible to consider the existence of excitatory pathways from the dominant motor cortex to the base nuclei of the contralateral hemisphere. This organization would explain not only the already evidenced function recovery when there is lesion of the dominant hemisphere ${ }^{(52-54)}$, but also the integrated bilateral stimulus that is observed, despite the inhibition of the sensorial and motor cortex of the non-dominant hemisphere. It is also possible to assume that these excitatory pathways exist in both directions.

Between the brainstem and the cortex, there are also interconnected pathways arriving at, and leaving from, the cerebellum, considered able to modulate muscular contraction intensity and sequence. In this way, cerebellar pathways connect with efferent voluntary (cortex-nuclear) pathways that will make synapses with the motor nuclei of the cranial nerves V, VII, IX and XII. From these nuclei, the efferent stimuli follow to the oral effectors, providing them with signaling of adequate contraction intensity and sequence, coordinated by the cortex and modulated by the cerebellum.

The bolus volume and viscosity will interfere with the muscular contraction intensity, defined by the cortex according to the oral qualification, to generate the necessary oral ejection. Nevertheless, the contraction activation sequence of the effectors will be common to all sequences involving the oral phase, suggesting that the neural organization has a predefined sequence. Taste and temperature do not exert influence on the oral muscular contraction intensity defined by the cortex. This observation means that, within limits of acceptability, chemical-reception, thermo-reception and certainly pain-reception do not interfere with the oral activity, which is governed by the mechanical reception, in particular volume and viscosity, which will affect the amount of motor units to be depolarized for an effective oral phase. The generation of the necessary and adequate muscular contraction intensity will be responsible for the information to be passed and maintained during the reflex phase of swallowing. The pressure intensity transferred by the oral phase will be the stimulus to be answered to by the neural control of the reflex pharyngeal phase. The esophageal phase, also reflex, should be influenced at least partly by the oral phase ${ }^{(57,58)}$.

One can describe the basic dynamics of the swallowing oral phase as follows: The Dental arcades touch one another by chewing muscle contraction (pair V). This dental arcades position allows skin-inserted muscles, in special buccinators and orbicularis oris (pair VII), to generate intraoral pressure resistance to prevent pressure escape out of the oral cavity during the bolus transference to the pharynx. The pressurized and resistant oral cavity will enable ejection of the bolus by the tongue (pair XII), which will transfer pressure and bolus to the pharynx. Still as part of the oral phase actions, the tensor veli palatini muscle (pair V) will provide resistance to the soft palate, which will be superiorly and posteriorly projected by the levator veli palatini muscle against the first fascicle of the pharynx superior constrictor muscle (pterygopharyngeus fascicle) at the beginning of the pharyngeal phase. The suprahyoid muscles elevate the hyoid and larynx, opening the pharyngeal-esophageal transition because it undoes the tweezers action between the vertebral body and larynx. The elevation of the hyoid and larynx that acts by undoing of the tweezers action, produced by the apposition of the larynx against the spine is coordinated mainly by the cranial nerves V and VII and also by $\mathrm{C} 1$ through the ansa cervicalis. The hyoid elevation starts at the end of the oral phase, and stays active till the end of pharyngeal phase. Contraction of the longitudinal stylopharyngeus muscle (IX) will reduce the pharyngeal distal resistance. Finally, in the end of oral 
phase, by possible involvement of the respiratory center on the floor of the fourth ventricle in the brainstem, swallowing apnea (preventive apnea) takes place. In sequence, but with an independent mechanism of apnea, beginning the pharyngeal phase, vocal folds adduction will occur. All the oral events remain active during the entire pharyngeal phase by assimilation of the reflex pharyngeal phase coordination ${ }^{(42,59-63)}$. (FIGURE 2).

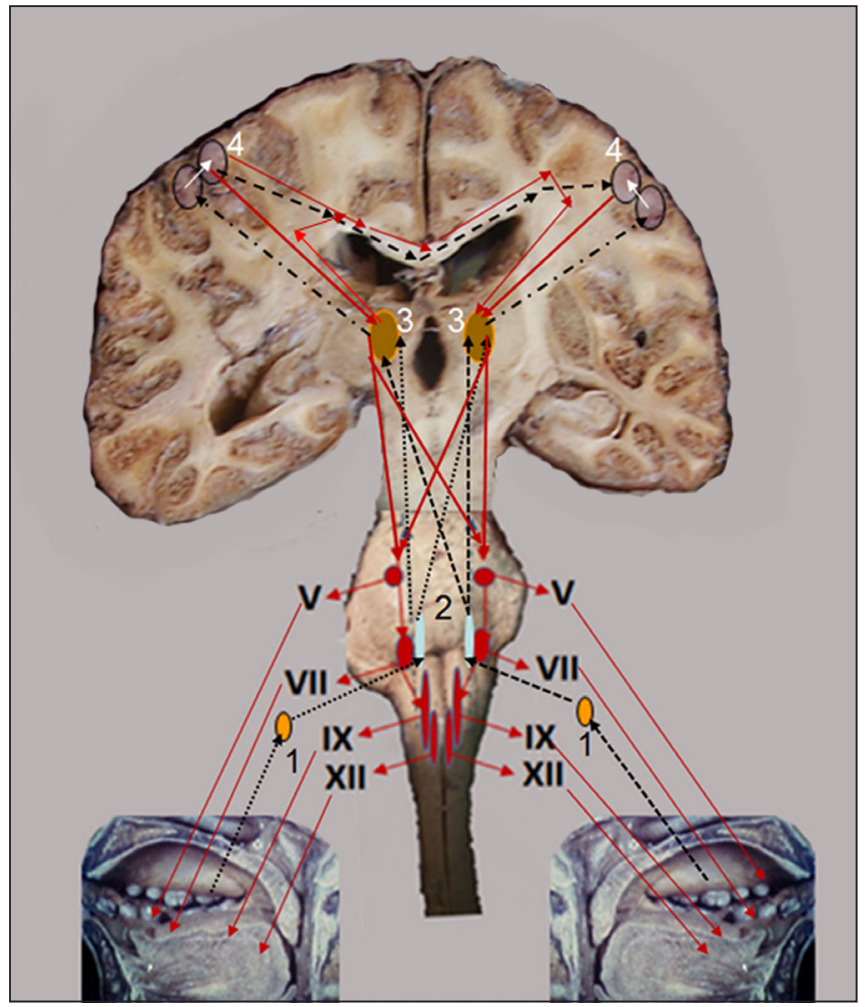

FIGURE 2. Frontal view of schematic diagram over an anatomical specimen representing the neural control of the nutritional oral phase. Black, dotted lines represent the oral afferent pathways that pass through the (1) sensorial ganglion and connect with sensitive nuclei of the solitary tract and nerve V nuclei in the brainstem (2). From there, they connect with the base nuclei (3) through direct and cross pathways. From the base nuclei (3), in nutritious swallowing the signals stimulate the postcentral (sensorial) and precentral (motor) gyruses (4), which start the efferent (motor) pathway. (Note 1: Sensory pathways do not exist in the primary cortical voluntary oral phase). Red, solid lines represent efferent motor pathways from the cortex to the base nuclei (3) and brainstem nuclei (2) where nerves V, VII, IX and XII conduct the stimuli (modulated by the cerebellum) to the oral effectors. (Note 2: In semiautomatic swallowing and while normality is maintained, motor responses are produced without cortical intervention). From the dominant hemisphere, there is an inhibiting pathway (black, dashed line) going to the opposite hemisphere and an excitatory pathway (red, solid line) and also to the base dominant nuclei to the non-dominant side.

\section{Primary cortical voluntary oral phase}

This type of oral phase reproduces all dynamic events observed in the nutritive oral phase of swallowing, without having any intraoral content to be qualified. It happens as if the cerebral cortex imagined a bolus with such known features, that the efferent cortical motor area reproduces an oral ejection with the same characteristics and using the same efferent pathways that it would if that imagined bolus could be exposed to oral receptors. Thus, this type of neural control does not have, as an integral part, the afferent signaling coming from the oral receptors to the sensitive cortex. In this way, the sequence from the motor cortex to the oral effectors will be exactly the same ${ }^{(58)}$.

\section{Semiautomatic oral phase}

This type of neural control is a temporary substitute for the one that occurs during the nutritional swallowing process. It replaces the voluntary control of the nutritional oral phase when, in a repetitive way, this has its parameters qualified and accepted as usual and within appropriate limits. In such cases, if the attention has been divided with another interest that demands cortical activity, swallowing control can be replaced by a semiautomatic control, which will be processed in subcortical level (base nuclei). Considering the proposed organization for the integration between base nuclei and cortex, we can hold that the base nuclei take control of the oral phase, maintaining its integrative activity, but repressing in their level the information brought from the periphery. Nevertheless, the base nuclei retain the ability to reactivate cortical control at any time, in particular if changes are detected ${ }^{(58)}$. I believe that the dominant hemisphere controls this semiautomatic process from its base nuclei, also through corpus callosum, on the same way of the inhibitory control.

\section{Subsequent gulps oral phase}

Subsequent gulps oral phase swallowing in subsequent gulps implies liquid intake that, in healthy individuals, demands depolarization of fewer motor units, because the necessary ejection force does not require too much effort. The control of this oral phase type of swallowing is, at least for the first gulp, similar to the control of nutritional swallowing. Although the material to ingest is liquid, a proper qualification is necessary, since it may have characteristics unexpected or distinct from the appearance. Taste, temperature and viscosity are assessed during the first gulp and, if accepted, go promptly to semiautomatic coordination, similar to that occurring in the nutritional diet. Here, the semiautomatic dynamics can start without requesting any other cortical attention, and without losing the basic perception of the gulps' characteristics. Like in nutritional swallowing, the resumption of the voluntary cortical control is immediate if desired or if any irregularity is perceived.

\section{Spontaneous oral phase}

Spontaneous oral phase is the swallowing that occurs to clarify oral cavity of the saliva produced and released in discrete volumes, but continuously. This type of oral phase occurs repeatedly over the course of the day's 24 hours, with the individual awake or asleep, in the absence of conscious control. These swallowing efforts generate a mechanical sequence similar to the other swallowing types with origin in the oral cavity. However, in some respect it is distinct in its trigger mechanisms. I believe that is possible to assume that this type of swallowing is due to the airways protective mechanism to prevent aspirations and compromising of the respiratory system. It has been demonstrated that the saliva adsorbed to the mucous membrane is capable of lubricating the laryngeal vestibule and vocal folds without producing discomfort. Also, the resulting volume of accumulated saliva would be compressed between the vestibular folds and epiglottis tubercle during swallowing with the adduced vocal folds, resulting in return of the residual saliva to the pharyn $x^{(64)}$. It is possible to believe that spontaneous swallowing is a product of this physiological airways permeation. 
The spontaneous swallowing that occurs repeatedly, being the individual awake or during sleep and in the absence of conscious control, seems to be the same semiautomatic swallowing observed in the nutritious swallowing sequence, though with a distinct trigger mechanism, probably related to airway protection.

Besides other functions, saliva is important in the chewing bolus preparation and in the lubrication of the mucous membranes to suitable transport. Saliva is produced in continuous volume and physical-chemical characteristics by the salivary glands, with mediation of parasympathetic fibers conducted by the cranial nerves VII (facial) and IX (glossopharyngeal).

Spontaneous swallowing helps in the distribution of saliva over the oral, pharyngeal and even vestibular mucosa, humidifying these membranes and probably helping to maintain fluid the mucus over the laryngeal ventricles. Inhalation and expiration dry the mucosa by the continuous airflow, and spontaneous swallowing keeps the moisture level of these mucous membranes. Spontaneous swallowing is also important for the control of small volume of liquids adsorbed to the laryngeal vestibule walls, removing any excess over this mucosa. During swallowing, with the adduced vestibule folds, the tubercle of the epiglottis presses against these folds, making the vestibule lumen virtual, expelling to the pharynx any excess existing there ${ }^{(58,64)}$.

\section{NEURAL CONTROL OF THE SWALLOWING PHARYNGEAL PHASE}

The reflex pharyngeal phase takes place without voluntary control or direct cortical command. This phase starts from the pharyngeal pressure stimulus transferred by the oral phase. In nutritional swallowing, after bolus qualification, in special in relation to volume and viscosity (mechanoreceptors), the oral ejection will transfer the qualified information (bolus and pressure) to the pharynx. From there the perceived stimulus go to the brainstem (solitary tract nucleus). In the brainstem, in special in the ambiguous nucleus, a motor reflex response will determine sequential muscle contractions in delay line based on the values qualified and transferred by the oral phase $\mathrm{e}^{(58,65,66)}$. Delay line is the contractile sequential muscular response of the muscles involved in the pharyngeal phase to a single pressure stimulus, which departs from the pharynx to the posterior sensory portion of the brainstem, and which returns to it via a ventral motor pathway, producing the sequential dynamics of the pharynx contractile activity. Although there is no direct motor cortex influence on the pharyngeal phase, the transferred content can be perceived, for example, for its temperature. This kind of perception means that there is afferent sensitivity, possibly to provide the oral transfer with tolerance limits.

The stimulus that triggers the pharyngeal phase is not the contact produced by the passage of food through the pharynx ${ }^{(67,68)}$, but the pressure that distends it, with or without contents ${ }^{(58,69)}$. In nutritional swallowing, food and pressure are transferred, but in cortical swallowing, only pressure is, and the pharyngeal response is similar to that of nutritious swallowing, indicating that the pressure distending the pharyngeal walls is the element that stimulates the pharyngeal motor activity ${ }^{(58)}$.

The pharyngeal distention pressure is identified and transferred to the brainstem through sensitive afferent fibers of the pharyngeal plexus (cranial nerves IX, X, XI). The glossopharyngeal (IX) nerves in the oropharynx and vagus and accessory ( $\mathrm{X}$ and $\mathrm{XI}$ ) in the laryngopharynx carry to the brainstem dorsal region (solitary tract nucleus - sensitive) the stimulus based on the pressure value transferred from the oral cavity to the pharynx. The dorsal region (sensitive) and the ventral one (motor) are integrated by interneurons of the brainstem's reticular system. A unique stimulus reaches the solitary tract nucleus, and motor reflex response is composed by a sequential action of several muscles in different times, configuring muscular sequential contraction in delay line.

It is reasonable to admit a cerebellum modulation over the pharyngeal reflex responses determined by the brainstem, explaining the sequential muscular contraction in the pharyngeal phase (delay line). Among its main functions, the cerebellum coordinates the temporal sequence of the synergic contraction of the different skeletal striated muscles, with the possibility to generate delay of the motor signals by fractions of a second, creating delay in the muscle contraction sequence ${ }^{(1,8,29)}$.

In a didactic way, and not failing to admit the possibility of a delay line control by inhibitory neurotransmitters, we have considered that the sensory-motor connection in the brainstem would be carried out by distinct amounts of synapses between interneurons connecting sensitive and motor nuclei, generating different transfer times between the solitary tract nucleus to the ambiguous one. Thus, a stimulus perceived by the pharyngeal receptors and transmitted to the solitary tract nucleus as unique would be retransmitted to the ambiguous nucleus, passing by a different and increasing number of interneurons, configuring the delay line observed in the swallowing pharyngeal phase.

Besides the sequence and intensity of muscular contraction determined by the brainstem from pressure reception, the pharyngeal phase incorporates or assimilates, as its functional part, the oral phase developments already in course. The oral phase incorporated elements and the pharyngeal phase will end together. Therefore, the brainstem, during the pharyngeal phase, integrates the sequence of the oral phase with the pharyngeal one. The pharyngeal phase starts by action of the pharyngeal plexus, composed of the glossopharyngeal (IX), vagus (X) and accessory (XI) nerves, with secondary involvement of the trigeminal (V), facial (VII), glossopharyngeal (IX) and the hypoglossal (XII), and also some elements of the cervical plexus $(\mathrm{C} 1, \mathrm{C} 2)$. The cervical plexus and the hypoglossal nerve on each side form the ansa cervicalis, from which a pathway goes to the geniohyoid muscle, one of the muscles that act in the elevation of the hyoid-laryngeal complex ${ }^{(58,65,70,71)}$.

The accessory (XI) nerve, not always considered among those associated with swallowing, is admitted as having special visceral efferent (motor) fibers originating from the ambiguous nucleus that would follow associated with the vagus nerve, which would also display this type of fiber ${ }^{(1,47)}$. Thus, the accessory (XI) nerve is also responsible for the motor innervation of the musculature of the palate, pharynx, larynx and esophagus, in association with the vagus nerve.

The pharyngeal phase shows adjustment, over the tongue on each side, of the palatoglossal muscle, innervated by the motor portion of the pharyngeal plexus $(\mathrm{X}, \mathrm{XI})$ to prevent pressure from returning to the oral cavity. The tension (V) and elevation of the palate (X, XI) against the first fascicle (pterygo-pharyngeal) of the upper constrictor muscle of the pharynx, innervated by the cranial nerves $\mathrm{X}$ and XI, blocks the possible pressure escape from the oropharynx to the rhinopharynx.

The superior, middle and inferior constrictor muscles of the pharynx are each one constituted of distinct parts, with individualized insertions. Each one of these parts is inserted in one side 
in anterolateral fixed points, and in the other, in the posterior median line of the pharynx (pharyngeal raphe). As a consequence of the individualization of their motor units, they can contract in sequential mode. The superior constrictor muscle has four parts (pterygopharyngeal, buccopharyngeal, mylopharyngeal and glossopharyngeal), the middle, two parts (chondropharyngeal and ceratopharyngeal), and the inferior, two parts (thyreopharyngeal and cricopharyngeal). The cricopharyngeal presents two fascicles, the upper, oblique, and the lower, transverse, whose fibers seems to cross with each other's in the midline. Between the two fascicles of the cricopharyngeal muscle, there is an anatomically less resistant area due muscular absence ${ }^{(72)}$.

The four parts of the superior constrictor occupy the entire extension of the oropharynx. Thus, it is necessary that only the first portion of its superior (pterygopharyngeal) part perform apposition against the palate, isolating and preventing pressure escapes from the oropharynx to the rhinopharynx. In the same time, the oral pressure can pass to the pharynx without resistance. The sequential contraction of the superior, middle and inferior constrictors' parts do not generate pharyngeal peristalsis, since there is no circular muscle on the pharyngeal wall. With closing of the pharyngeal contiguous cavities except for the pharyngealesophageal transition, which opens as a result of the elevation of the hyoid and larynx, there is a constrictors muscle contraction generating a pressure sequence in the cranial-caudal direction. This pressure sequence displaces the transient bolus from the pharynx to the permissive, less resistant esophagus by the opening of the pharyngeal-esophageal transition ${ }^{(42,70)}$.

By definition, peristalsis is a sequential expression produced by a muscle circular layer. In this way this cranial-caudal pressure sequence with distal less resistance without muscle circular layer should not be considered as peristalsis or peristalsis like as is often defined.

The suprahyoid muscles are innervated by the cranial nerves $\mathrm{V}$ and VII and by the $(\mathrm{C} 1)$ cervical plexus, connected via ansa cervicalis with the hypoglossal nerve. The mylohyoid branch of mandibular nerve (mixed root of trigeminal - V) innervates the mylohyoid and the anterior belly of the digastric muscles; the posterior belly of the digastric and the stylohyoid muscles, by the facial nerve (VII). The geniohyoid and thyrohyoid muscles are innervated by ansa cervicalis (usually $\mathrm{C} 1$ ) through the hypoglossal (XII) nerve. The cervical plexus (usually C2) through the ansa cervicalis innervate the other infrahyoid muscles. The suprahyoid muscle group is responsible for the forward and upward movement of hyoid and larynx, with modulation by the infrahyoid group. This action moves the larynx away from the vertebral body and opens the pharyngeal-esophageal transition. Moreover, while moving the larynx away, the suprahyoid group is able to sustain this open condition depending on the bolus volume and viscosity. The opening of the pharyngeal-esophageal transition is also enhanced by the contraction of the longitudinal pharyngeal muscles, the stylopharyngeal ones, innervated by the glossopharyngeal (IX) nerve, and the palatopharyngeal muscle, innervated by motor fibers from cranial nerves $\mathrm{X}$ and $\mathrm{XI}^{(42,65,71,72)}$.

Still in the oral phase, as a last act, a preventive apnea (swallowing apnea) ensues, being assimilated by the pharyngeal phase and remaining until its end. Associated with the airways resistance produced by apnea, there is independent vocal folds adduction (X, $\mathrm{XI}$ ), followed by closure of the vestibular folds with the bolus passage through the already open pharyngeal-esophageal transition. The adduction of the vestibular folds is due to the compression of the pre-epiglottic fatty cushion produced by the elevation of the hyoid and larynx, which compresses this cushion contained in the pre-epiglottic fibrous space. This space has, as its point of least resistance, the lateral aspects of the tapered end of the epiglottis, which corresponds to the projection of the vestibular folds on both sides. Thus, the compression produced by this fatty cushion on the sides of the epiglottis causes the medial shift of the vestibular folds, which end up in apposition against the epiglottis tubercle. On its turn, the epiglottis, everted by the tongue, moves posteriorly, adjusting its tubercle against the now adduced vestibular folds ${ }^{(59-62)}$. At the same time, the constrictor muscles' parts, including the crycopharingeal one, carry out the sequential, cranio-caudal contraction (nerves $\mathrm{X}$ and $\mathrm{XI}$ ), driving the bolus from the pharynx into the esophagus ${ }^{(62,63)}$. (FIGURE 3).

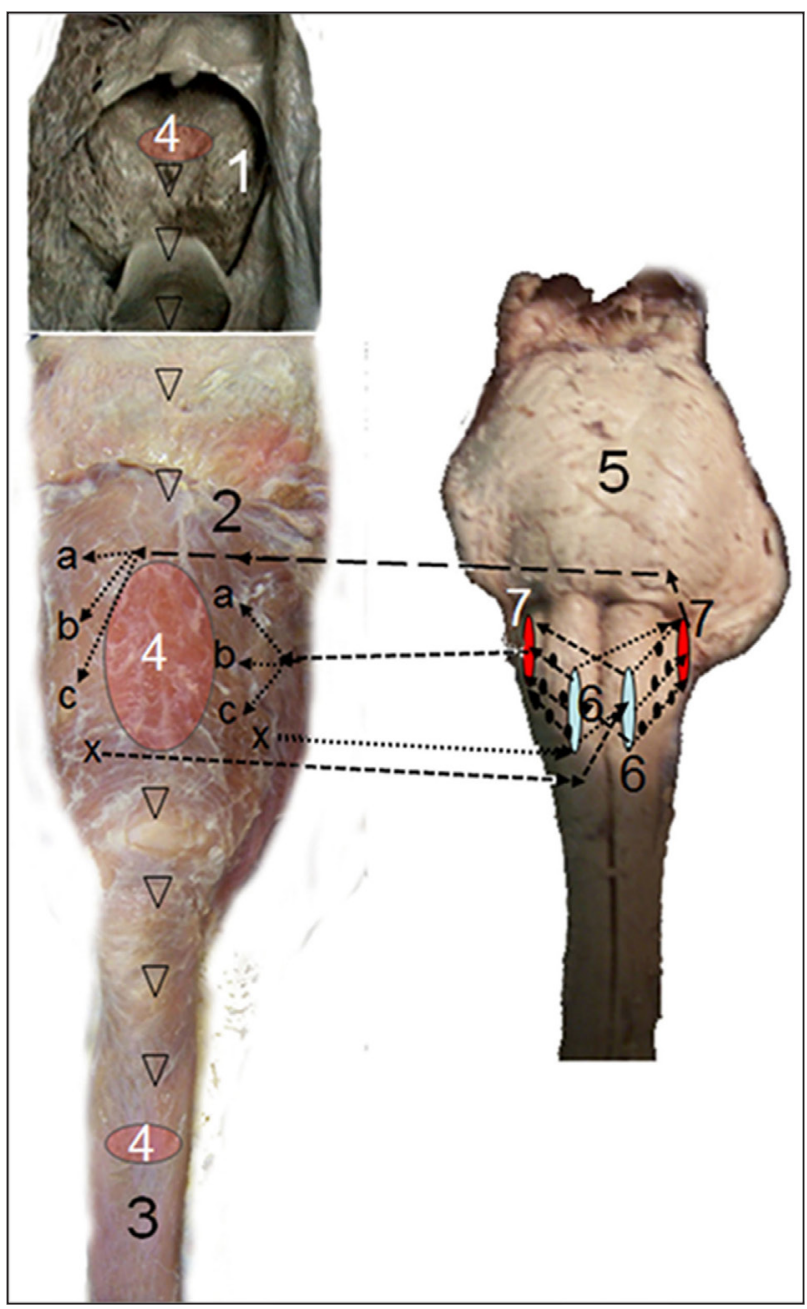

FIGURE 3. Neural control representation of the pharyngeal phase over anatomical specimens where 1 - oral cavity, 2 - pharynx, 3 - esophagus, 4 - swallowed bolus, 5 - brainstem, X - pharyngeal receptors, 6 solitary tract nucleus, 7 - Ambiguous nucleus. Over 5, lower dotted arrows from six to six - afferent integration, and upper dotted arrows from six to seven - efferent integration. From 6 (sensitive nucleus) to 7 (motor nucleus), multi-dotted arrows are a didactic representation of the growing number of interneurons of the delay line. From 7 (ambiguous nucleus) to $a, b$, and $c$ on both sides, dashed arrows represent the efferent stimulus to muscle delay line. There is pressure transference from 1 to 2 (pharyngeal distention), represented by widening of 4 . Hollow arrowheads show displacement of the bolus (4) from mouth to esophagus. 
The pharyngeal and esophageal phases, both reflex, present anatomical and functional relation. The firsts $10 \mathrm{~cm}$ of the esophagus are formed by skeletal striated muscle, like the oral and pharyngeal ones. In the distal extremity of this striated segment, by 2 or $3 \mathrm{~cm}$, a muscular distinction is identified macroscopically in fresh anatomical specimens, which is microscopically defined as a mixture of skeletal striated muscle (long and multinucleated fibers) and fibers of smooth muscle (short and mono-nucleated), where the first ganglion of the myenteric plexus appears ${ }^{(73)}$. (FIGURE 4).

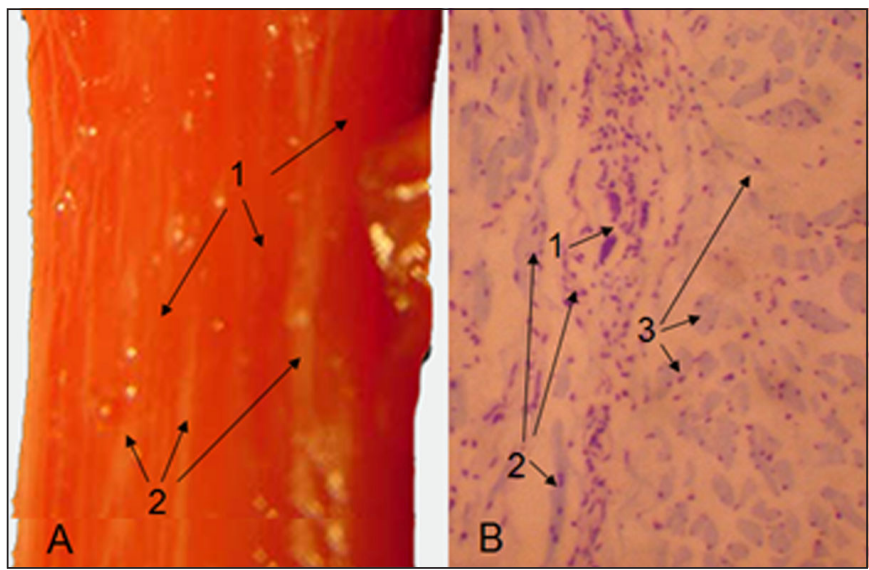

FIGURE 4. A - fresh esophagus segment where there is mixture of 1 - smooth and 2 - striated muscle. B - histological specimen obtained from (A), with (1) first ganglion of the myenteric plexus and mixture of long and multinucleated striated muscle fibers (2) and short and mononucleated smooth ones (3).

The high-pressure zone designated as the upper esophageal sphincter is located at the distal pharynx, where a tweezer action closes the pharynx between the larynx (cricoid cartilage) and the cervical lordosis at the level of the 5th to 6th cervical vertebrae. Usually this high pressure is considered as due to the maintained contraction of the cricopharyngeal muscle, part of the inferior pharyngeal constrictor. This conception is a severe misunderstanding about the anatomical and functional characteristics of this region. The inferior constrictor of the pharynx is a skeletal striated muscle consisting of two fascicles (thyropharyngeal and the cricopharyngeal). The cricopharyngeal fascicle presents two parts of fibers in its organization, an upper, oblique and a lower, transverse. The upper one inserts on each side of the cricoid cartilage, from where its fibers go from the bottom upwards and from lateral to medial, inserting on the posterior pharyngeal raphe. The lower or transverse part inserts on each side of the cricoid cartilage, with a transverse direction, intercrossing in the midline, where the raphe cannot be seen. The width of the pharyngeal lumen at the level of the transverse cricopharyngeal part is about $17 \mathrm{~mm}$ and there is not muscular ring in this region, which can be described as a muscular half-curvature. The divergence between the oblique and transverse parts of the cricopharyngeal muscle creates an intermediary zone without muscular fibers that constitutes an anatomically less resistant point, already described as the Kilian zone, where the posterior pharyngeal diverticulum, known as Zenker's diverticulum, can occur. This anatomically less resistant area is coincidentally the point of higher-pressure values, certainly due to the tweezer action produced by the vertebral body and the $\operatorname{larynx}^{(65,71)}$. (FIGURE 5).

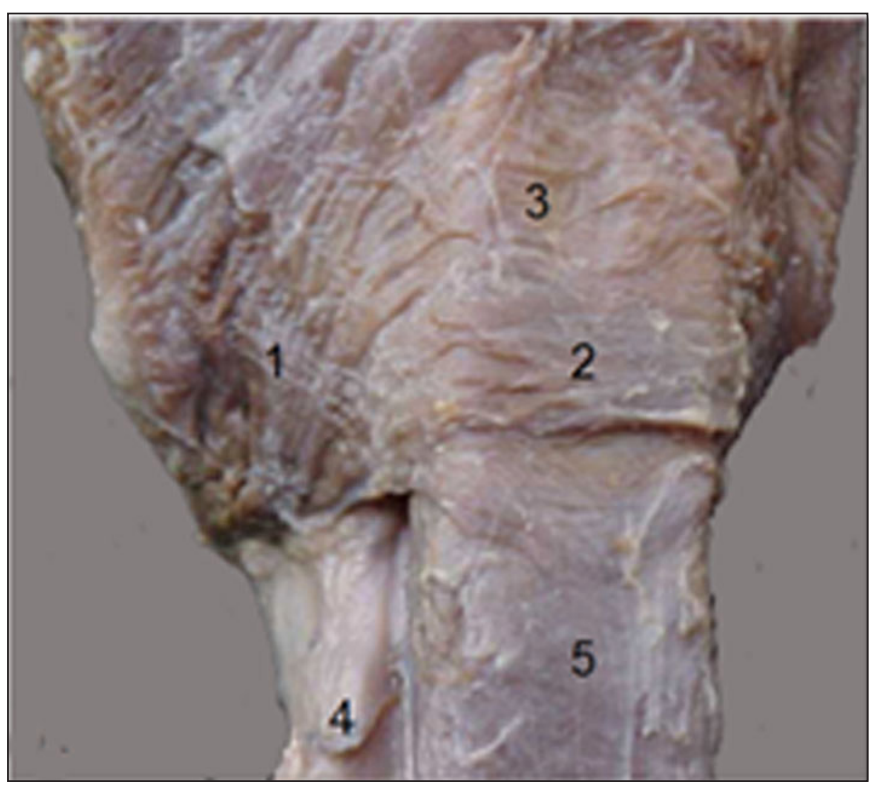

FIGURE 5. Posterior view of anatomical specimen involving the pharynx, larynx, esophagus and trachea, where 1 - Cricopharyngeal muscle, oblique fascicle, 2 - Cricopharyngeal muscle, transverse fascicle, inserted on the larynx cricoid cartilage, 3 - Kilian zone, the anatomically less resistant zone on the posterior pharyngeal wall where the pharyngeal diverticulum described by Zenker occurs. This less resistant zone is due to the divergence of the oblique and transverse fascicles of the cricopharyngeal muscle. 4 - Trachea, 5 - Esophagus.

The cricopharyngeal muscle has been known as a skeletal striated muscle type that demands expressive consumption of ATP (adenosine triphosphate), because it depends on ATP both to contract and to relax. In order to demonstrate that the cricopharyngeal muscle is not contracted at rest, only to relax when the pharyngeal-esophageal transition opens, as believed by many, we performed manometry of the pharyngeal-esophageal transition. This manometry was carried out with a balloon built with a latex glove finger to measure the positive pressure resistance of the pharyngeal-esophageal transition of 12 fresh corpses, in the first 6 to 12 hours postmortem. This research were permitted by an agreement between the Anatomy Department of the Biomedical Sciences Institute of the Federal University of Rio de Janeiro (Universidade Federal do Rio de Janeiro - UFRJ) and the Legal Medical Institute of Rio de Janeiro, Brazil.

The balloon traction shows that positive pressure values remain present on the pharyngeal-esophageal transition in all studied fresh corpses. A second pressure verification, with insertion of a metallic prosthesis between the vertebral body and the larynx, shows absence of resistance in this region, where the prosthesis eliminates the tweezer mechanism of the larynx against the vertebral body. Based on the positive values observed in the first measure and absent in the second, with the prosthesis insertion, we concluded that resistance on the pharyngeal-esophageal transition is dependent on the tweezer action of the larynx against the vertebral body. (FIGURE 6).

In two cricopharyngeal muscles, we also carried out electric stimulation, including analysis of tolerance to calcium pump inhibitors (verapamil) and polyacrylamide gel electrophoresis with dodecyl sodium sulfate paired with other striated muscles. 


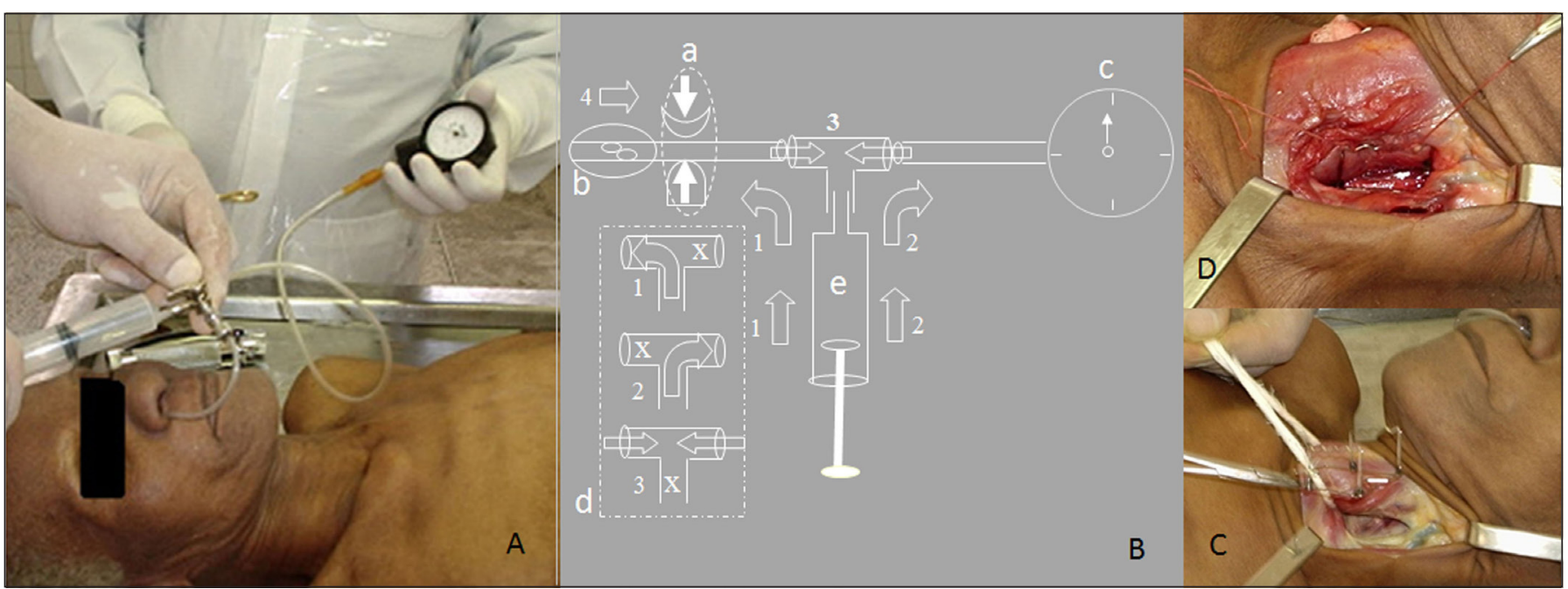

FIGURE 6.A. Manometry on a fresh corpse. B. Scheme highlighting (a) - pharynx between tweezer formed by vertebral body and larynx that compresses the pharynx at rest, (b) - elastic and distensible balloon, and (c) - sphygmomanometer. (d) - rectangle containing three possibilities of pressurization of the system, where X represents flow closure, 1 and 2 represent air flow to be balanced with the distended balloon, and 3, the three-way tube that allows the balance of pressures, (e) - syringe, 4 - direction of balloon traction. C. After verification of basal pressure (positive in all 12 cases), cervical dissection for passage of a metallic prosthesis separating the larynx from the spine. D. Prosthesis installed for re-verification (absence of positive pressure in all 12 cases).

We obtained these two cricopharyngeal muscles from specimens immediately resected from total laryngectomies, with surgical indication and consent. These muscles showed the same characteristics of other striated muscles under electric stimulation, including their tolerance to calcium pump inhibitors. The electrophoresis paired with other striated muscles revealed the same protein patterns and molecular weights. These two experiments allow the conclusion that the cricopharyngeal muscle has morphology and function of a striated muscle. (FIGURES 7 and 8).

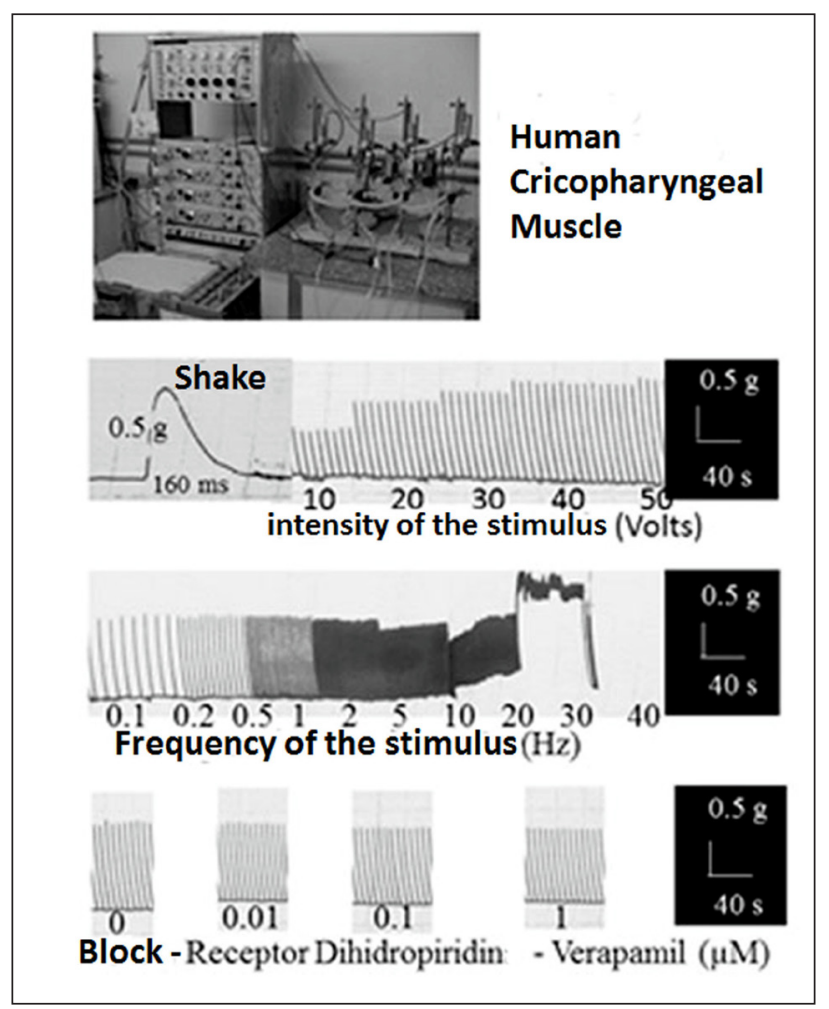

The open pharyngeal-esophageal transition intercommunicates the pharynx and esophagus, allowing the video-fluoroscopic examination to show the flow of contrast medium filling both cavities almost simultaneously. One can observe that the pharyngeal and esophageal cavities present a relation with the contrast medium that occurs during the time of the pharyngeal phase. Thus, the beginning of the esophageal phase occurs, practically, in the same time of the pharyngeal phase, demonstrating the clear functional relationship between these reflex phases, which is so much or more consistent than the observed between the oral and pharyngeal phases. This fact demonstrates that the pharyngeal and esophageal phases are responsible for the conduction of the contents transferred by the oral phase ${ }^{(61,74)}$. (FIGURE 9).

\section{NEURAL CONTROL OF THE SWALLOWING ESOPHAGEAL PHASE}

The sequential contraction of pharyngeal muscles leads the bolus transferred by pharyngeal pressure. It results from the special visceral efferent innervation conducted by the vagus nerve, originating in the ambiguous nucleus, also responsible for the striated muscle of the upper portion of the esophagus. The bolus inside the esophagus is conducted by sequential contractions in distal direction, defined as primary peristalsis.

The mechanical relation between bolus and smooth muscle in the esophagus wall will be able to stimulate this kind of muscle, unlike striated one. The smooth muscle in the esophagus wall will

FIGURE 7. Polygraphic record of isometric tension of the cricopharyngeal muscle. On top, the polygraph used. The first bar shows constant increase of the contraction force as the stimuli intensity (Volts) increases. The second bar shows gradual contraction frequency increase of the cricopharingeal muscle with the stimuli pace $(\mathrm{Hz})$ increment, until the installation of tetany. The third bar shows the use of verapamil (calcium pump blocker) in increasing concentrations: both in the absence and with increasing doses of the calcium pump blocker, the muscle behavior is the expected for skeletal striated muscle. The three bars therefore register a skeletal striated muscle behavior. 


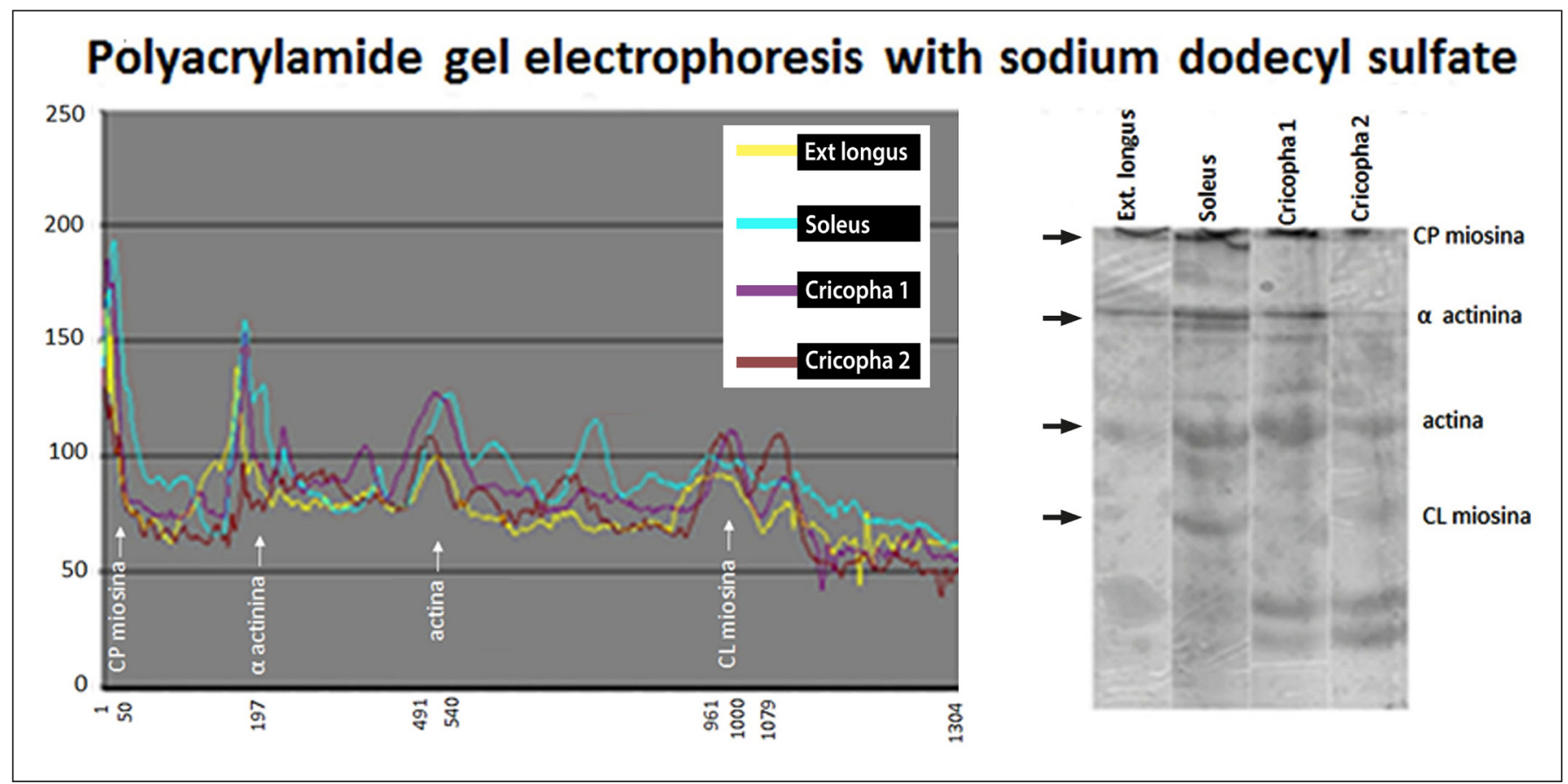

FIGURE 8. Protein Electrophoresis. On the right side, protein fractions distribution near the same plane for the four tested muscle samples, where two are cricopharyngeal samples and two other muscles previous known as striated (extensor halluces longus and soleus muscle). On the left, superposition of the protein weights of the four tested muscle samples, confirming that the cricopharyngeal muscles has the similar protein fractions distribution of the previous known as striated muscle.

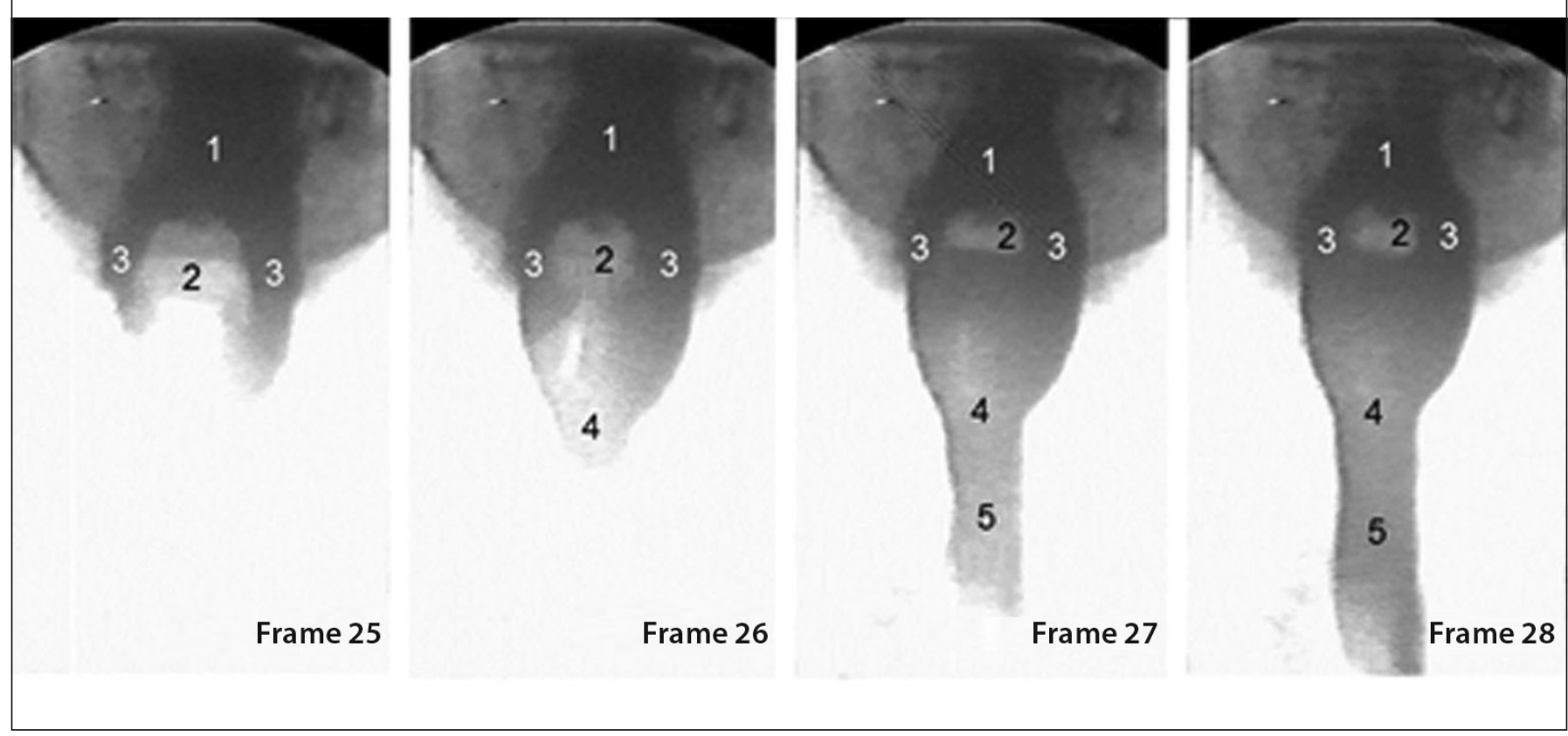

FIGURE 9. Video-fluoroscopic examination of swallowed contrast media. 1 - Oropharynx, 2 - Epiglottis, 3 - Piriform recesses, 4 - Pharyngealesophageal transition, and 5 - Esophagus. The pharyngeal phase begins at frame 20 and ends at 50 , with total time of 0.99 sec. (each frame lasts $0.033 \mathrm{msec}$.). After 0.2 to $0.23 \mathrm{sec}$. (frame 26 to 27), the esophageal phase is already starting in superposition with the pharyngeal one. The epiglottis remains in the vertical position and will only close the pharyngeal-esophageal communication (horizontal position) at the end of the pharyngeal phase, in frame 45. At this time, the pharynx, with residual volume, starts its return to resting position, with closure of the pharyngeal-esophageal transition by the return of the larynx in opposition to the vertebral body and with the epiglottis in vertical position. 
be depolarized in a syncytial way, where the depolarization of the muscle cells is freely transferred from one to the other, with contraction processed in the entire extension of the muscle layer. Thus, we can consider, as a hypothetical mechanism, that the contents transferred from the pharynx to the esophagus while in its striated portion are conducted similarly to the way that takes place in the pharynx, by depolarization of motor units. Nevertheless, when the bolus passes through the striated/smooth transition, it is capable of stimulating the myenteric plexus from this transition on, generating syncytial contraction. This syncytial depolarization is able to cause contraction of the longitudinal layer, reducing the resistance of the esophagus as a whole, increasing its complacency and culminating, or at least participating, in the opening of the gastroesophageal transition that occurs in concomitance with the onset of primary peristalsis. It is also possible that the circular musculature depolarizes and contracts during the bolus passage through the striated/ smooth transition, in association with the primary peristalsis. This contraction pressurizes the esophageal lumen downwards, leading the bolus in transit through the esophagus ${ }^{(75-76)}$.

The pharynx and the esophagus first portion are both formed by striate muscle innervated by the special visceral efferent (motor) pathway of the vagus nerve. This cranial nerve also has the general visceral efferent (parasympathetic) pathway, which is preganglionic to the myenteric plexus. In this way, another hypothesis would be that the esophageal smooth muscle motor coordination be done by myenteric postganglionic stimulation in sequence with the special visceral efferent pathway (motor to striate muscle) in association with the general visceral efferent pathway (parasympathetic - motor to smooth muscle) of the vagus nerve.

The contents transferred from the pharynx to the esophagus, notably the ones with solid fragments, not always reach the stomach. Sometimes they stop at the level of the esophagus smooth muscle, from where they are able to locally stimulate the submucosal plexus, which transfers an activation command to the myenteric plexus, producing muscle contraction from the retention point on. This downward contractile wave is defined as secondary peristalsis, which ends up conducting the residual esophageal contents to the stomach ${ }^{(73)}$.

It has been considered that the general visceral efferent pathway (parasympathetic fibers) originating in the posterior motor nucleus of vagus as preganglionic fibers will connect to intraparietal ganglia in the esophageal wall, from where postganglionic fibers connect with visceral effectors that release neuro-hormones capable of interfering with the tonus and motility of the smooth portion of the esophagus ${ }^{(1)}$. It is also believed that the esophagus distal extremity presents resting tonic contraction involving the distal circular musculature. Hormones would regulate this resting tonic contraction in association with intrinsic and extrinsic nerves that generate pressure values around $20 \mathrm{mmHg}$. This prevailing hypothesis considers that the gastroesophageal transition opens to due muscle relaxation that would occur in association with the primary peristalsis, induced by vagus fibers that would inhibit the tonic contraction of the circular musculature, with possible mediation of VIP (vasoactive intestinal polypeptide) neurotransmitters and NO (nitric oxide) $)^{(77)}$.

Despite the prevailing concepts, it has not been identified, in the distal portion of the esophagus, a muscular ring with the classical characteristics observed in smooth muscle sphincters. However, the gastroesophageal transition, without muscular thickening, presents positive resting pressure, which fades away during the primary peristaltic wave that leads the bolus to the stomach. Due to the lack of knowledge about the morphology responsible for the high pressure of this transition defined as cardia, it has been deemed a physiological sphincter. This situation has given rise to speculations that add up to about 27 possible mechanisms, isolated or in association, including those involving the regional muscle organization ${ }^{(74)}$.

The esophagus presents an internal layer, defined as circular, and another external, as longitudinal. The external one, when contracting, reduces the resistance of the esophageal tube, and the internal propels the bolus in sequential contraction. It is possible that the esophageal muscular layers are arranged in a way that the external layer displays long-pitch, spiral fibers, and the internal one, short-pitch, spiral fibers. This morphology, associated with the concept of energy preservation, allows us to admit that the contraction of the external layer would be able to widen the esophagus, decreasing the resistance to the flow, probably also by opening the gastroesophageal transition. On its turn, the internal layer would propel the food downwards by sequential contraction. Thus, during the resting esophageal stage, there would be no energy expenditure $\mathrm{e}^{(58,73,74)}$. The opening of the gastroesophageal transition would be an active response to the esophageal peristalsis that would activate the myenteric plexus during the entry of the bolus into the esophagus. Corroborates this hypothesis the fact that the esophagus, when subjected to pure pressure distension, responds differently than in the presence of the concrete bolus. 
Costa MMB. Controle neural da deglutição. Arq Gastroenterol.

RESUMO - Contexto - A deglutição é um processo motor com muitas discordâncias e de difícil estudo quanto a sua neurofisiologia. Talvez por essa razão sejam tão raros os artigos sobre esse tema. Objetivo - Descrever o controle neural da mastigação e a qualificação do bolo que se obtém durante a fase oral. Revisar os nervos cranianos envolvidos com a deglutição e suas relações com o tronco cerebral, cerebelo, núcleos de base e córtex. Métodos - Revisão da literatura com inclusão de trabalhos pessoais e novas observações buscando dar consistência a necessária revisão dos conceitos, muitas vezes conflitantes. Resultados e Conclusão - Em relação a fase oral da deglutição consideramos o controle neural em cinco distintas possibilidades. Fase oral nutricional voluntária, fase oral cortical voluntária primaria, fase oral semiautomática, fase oral em goles subsequentes e fase oral espontânea. Em relação ao controle neural da fase faríngea da deglutição, pode-se observar que o estímulo que dispara a fase faríngea não é o toque produzido pela passagem do bolo, mas sim a distensão pressórica, tenha ou não conteúdo em passagem. Na deglutição nutricional, alimento e pressão são transferidos, mas na fase oral da deglutição primária cortical somente pressão é transferida e temos resposta faríngea similar a nutricional. A fase faríngea incorpora como parte de sua dinâmica as atividades orais já em curso. A fase faríngea se inicia por ação do plexo faríngeo composto pelos nervos glossofaríngeo (IX), vago (X), e acessório (XI), com envolvimento do trigêmeo (V), do facial (VII), glossofaríngeo (IX) e hipoglosso (XII). O plexo cervical $(\mathrm{C} 1, \mathrm{C} 2)$, e o nervo hipoglosso, a cada lado, formam a alça cervical de onde, com origem cervical, um ramo segue para o músculo gênio-hioide, um músculo que atua na dinâmica de elevação do complexo hiolaríngeo. Foi também considerado o controle neural da fase esofágica da deglutição. Além de outras hipóteses foi considerado que é possível que a camadas musculares consideradas como longitudinal e circular para o esôfago sejam a longitudinal composta por fibras espirais de passo longo e a circular por fibras espirais de passo curto. Essa morfologia associada ao conceito de preservação de energia, nos permite admitir que a contração da camada longitudinal por seu arranjo espiral seja capaz de alargar o esôfago diminuindo sua resistência ao fluxo e provavelmente e também abrindo a transição esofagogástrica. Desse modo a camada circular, espiral de passo curto, pode propelir o bolo por constrição sequencial de cranial para caudal.

DESCRITORES - Deglutição. Nervos cranianos. Tronco encefálico. Gânglios da base. Córtex cerebral. Vias neurais.

\section{REFERENCES}

1. Erhart E A. Neuroanatomia simplificada. 6ed ed. São Paulo: Roca; 1986.

2. Ertekin C, Aydogdu I. Neurophysiology of swallowing. Clin Neurophysiol. 2003;114:2226-44

3. Miller AJ. Deglutition. Psysiol Rev. 1982;62:129-84.

4. Rosso ALZ. Controle neural da deglutição. In: Temas em deglutição \& disfagia: Abordagem multidisciplinar. Rio de Janeiro; 1998. p. 13-6.

5. Roman C. Neural control of deglutition and esophageal motility in mammals. J Physiol. 1989;81:118-31

6. Bieger D. Rhomboncephalic pathways and neurotransmitters controlling deglutition. Am J Med. 2001;111:85S-89S.

7. Machado A. Neuroanatomia funcional. 2ed ed. Atheneu, editor. São Paulo; 1993

8. Guyton AC, Hall JE. Textbook of medical physiology. 10 ed. Philadelphia, PA: Saunders Elsevier, 2011.

9. Jean A. Brain stem control of swallowing: neural network and cellular mechanisms. Physiol Rev. 2001;81:929-69.

10. Ertekin C. Electrophysiological evaluation of oropharyngeal dysphagia in Parkinson's disease. Mov Disord. 2014;7:31-56.

11. Jean A, Car A, Roman C. Comparison of afctivity in pontine versus medullary neurons during swallowing. Exp Brain Res. 1975;22:211-20.

12. Jean A. Brainstem organization of the swallowing network. Brain Behav Evol. 1984;25:109-16.

13. Kessler JP, Jean A. Identification of the medullary swallowing regions in the rat. Exp Brain Res. 1985;57:256-63.

14. Umezaki T, Matsuse T, Shin T. Medullary swallowing-related neurons in the anesthetized cat. Neuroreport. 1998;9:1793-8.

15. Ertekin C. Neurogenic Dysfhagia in Brainstem Disorders and EMG Evaluation. J Basic Clin Heal. 2017;1:1-10.

16. Jean A. Control of the central swallowing program by inputs from the principal receptors. A review. J Auton Nerv Syst. 1984;10:225-33.

17. Aydogdu I, Ertekin C, Tarlaci S, Turman B, Kiylioglu N, Secil Y. Dysphagia in lateral medullary infarction (Wallenberg's syndrome): an acute disconnection syndrome in premotor neurons related to swallowing activity. Stroke. 2001;32:2081-7.

18. Jean A, Dallaporta M. Electrophysiologic characterization of the swallowing pattern generator in the brainstem. GI Motil. 2006;9:1-37.

19. Ertekin C, Pehlivan M, Aydogdu I. An electrophysiological investigation of deglutition in man. Muscle Nerve. 1995;18:1177-86.

20. Ertekin C. Voluntary versus spontaneous swallowing in man. Dysphagia. 2011;26:183-92.

21. Ertekin C, Aydogdu I, Yüceyar N. Effects of bolus volumes on the oropharyngeal swallowing: an electrophysiological study in man. Am J Gastroenterol 1997;92:2049-53.
22. Miller AJ. The neuroscientific principles of swallowing and dysphagia. San Diego, CA/London: Singular Publication Group; 1999.

23. Jean A, Car A. Inputs to swallowing medullary neurons from the peripheral afferent fibers and swallowing cortical area. Brain Res. 1979;178:567-72.

24. Perlman AL, Schlze-Delrieu KS. Deglutition and its disorders: Anatomy, physiology, clinical diagnosis and management. San Diego: Singular Publication Group; 1997.

25. Ertekin C, Aydogdu I, Yüceyar N, Tarlaci S, Kiylioglu N, Pehlivan M. Electrodiagnostic methods for neurogenic dysphagia. Electroenceph Clin Neurophysiol. 1998;109:331-40.

26. Jean A, Amri M, Calas A. Connections between the medullary swallowing area and the trigeminal motor nucleus of the sheep studied by tracing methods. J Auton Nerv Syst. 1983;7:87-96.

27. Costa MMB. Disfagia oral e ou faríngea e os distúrbios referentes. Rio de Janeiro: Medbook; 2013. 180-95 p.

28. Machado A. Nervos cranianos. In: Neuroanatomia funcional. 2ed ed. São Paulo: Atheneu; 2006. p. 119-28.

29. Chusid JG. Neuroanatomia correlativa e neurologia funcional. 18ed ed. Rio de Janeiro: Guanabara Koogan; 1985.

30. Pansky B, Allen DJ. Cranial Nerves. In: Review of neuroscience. New York: MacMillan Publishing; 1980. p. 223-54.

31. Guyton AC. Os sentidos químicos. In: Tratado de fisiologia médica. Rio de Janeiro: Guanabara Koogan; 1992. p. 512-4.

32. Rhodes RA, Pflanzer RG. Sensory systems. In: Human Physiology. 3 ed. Philadelphia: Saunders; 1996. p. 252-97.

33. Lent R. Os sentidos químicos. Estrutura e função do sistema gustatório. In: Cem bilhões de neurônios: conceitos fundamentais. São Paulo: Atheneu; 2001. p. 324-30.

34. Berne RM. The chemical senses. In: Physiology. 4 ed. St. Louis: Mosby; 1998. p. 178-85.

35. Esbérard CA. Sensibilidade especial. In: Fisiologia. Rio de Janeiro: Guanabara Koogan; 1991. p. 246-8.

36. Henkin RI, Christiansen RL. Taste localization on the tongue, palate and pharynx of normal man. J Appl Physiol1. 1967;22:316-20.

37. Estrela F, Schneider FL, Aquini MG, Marrone ACH, Steffani MA, Jotz GP Controle neurológico da Deglutição. In: Tratado de Deglutição e Disfagia - No adulto e na criança. Rio de Janeiro: Revinter; 2009. p. 20-34.

38. Schiffman S. Taste and smell losses in normal aging and disease. Jama. 1997;278:1357-62.

39. Warwick R, Willians PL. O aparelho gustatório. In: Gray Anatomia. 18ed ed Rio de Janeiro: Guanabara Koogan; 1979. p. 1016-8.

40. Lindemann B. Receptor and transduction in taste. Nature. 2001;413:219-25. 
41. Costa MMB, Santana E, Almeida J. Oral taste recognition in health volunteers. Arq Gastroenterol. 2010;47:152-8.

42. Costa MMB. Fase oral da deglutição. In: Deglutição \& Disfagia - Bases morfofuncionais e videofluoroscópicas. Rio de Janeiro: Medbook; 2013. p. 70-90.

43. Nanci A. Mucosa oral. In: Tem Cate-Histologia oral: Desenvolvimento, estrutura e função. Rio de Janeiro: Elsevier RJ; 2013. p. 278-310.

44. Bajec MR, Pickering GJ. Thermal taste, PROP responsiveness, and perception of oral sensations. Physiol Behav. 2008;95:581-90.

45. Cruz A, Green BG. Thermal stimulation of taste. Nature. 2000;403:889-92.

46. Bittencourt JC, Costacurta L, Manubens RS, Andrade EP, Zorzetto NL. Estudo anatômico dos ramos linguais do nervo lingual em indivíduos brasileiros adultos. Ver Bras Cien Morfol. 1987;4:115-21.

47. Dantas AM. Nervos cranianos motores. In: Os nervos cranianos - Estudo anátomo-clínico. Rio de Janeiro: Guanabara Koogan; 2005. p. 15-46.

48. Hamdy S, Aziz Q, Rothwell JC, Singh KD, Barlow J, Hughes DG, et al. The cortical topography of human swallowing in health and disease. Nat Med. 1996;2:121-24.

49. Hamdy S, Mikulis DJ, Crawley A, Xue S, Lau H, Henry S, et al. Cortical activation during human volitional swallowing: an event-related fMRI study. Am J Physiol Gastrointes.t Liver Physiol. 1999;277:G219-25.

50. Hamdy S, Rothwell JC, Brooks DJ, Bailey D, Aziz Q, Thompson DG. Identification of the cerebral loci processing human swallowing with H2 $15 \mathrm{O}$ PET activation. J Neurophysiol. 1999;81:1917-26.

51. Martins RE, Sesse BJ. The role of the cerebral cortex in swallowing. Dysphagia. 1993;8:195-202.

52. Hamdy S, Aziz Q, Rothwell JC, Power M, Singh KD, Nicholson DA, et al. Recovery of swallowing after dysphagic stroke relates of functional reorganization in the intact motor cortex. Gastroenterology. 1998;115:1104-12.

53. Li S, Luo C, Yu B, Yan B, Gong Q, He C, et al. Functional magnetic resonance imaging study on dysphagia after unilateral hemisferic stroke: a preliminar study. J Neurol Neurosurg Psychiatry. 2009;80:1320-9.

54. Teismann IK, Suntrup S, Warnecke T, Steinstrater O, Fischer M, Floel A, et al Cortical swallowing processing in early subacute stroke. BMC Neurol. 2011;11:34.

55. Penfield W, Jasper H. Epilepsy and the functional anatomy of the human brain. Ed. Oxford. England: Little, Brown \& Co; 1954

56. Hogan RE, English EA. Epilepsy and brain function: commons ideas of Hughlings-Jckson and wilder Penfield. Epilepsy Behav. 2012;24:311-3.

57. Costa MMB. Dinâmica da deglutição. In: Deglutição \& disfagia- Bases morfofuncionais e videofluoroscópicas. Rio de Janeiro: Medbook; 2013. p. 38-45.

58. Costa MMB. Controle neural da deglutição. In: Deglutição \& disfagia- Bases morfofuncionais e videofluoroscópicas. Rio de Janeiro: Medbook; 2013. p. 48-68.
59. Costa MMB. Mecanismos de proteção das vias aéreas. In: Disfagia: Abordagem clínica e cirúrgica - criança, adulto e idoso. Rio de Janeiro: Elsevier; 2017. p. 23-32.

60. Costa MMB. Mecanismo de proteção de vias aéreas. In: Tópicos em deglutição \& Disfagia. Rio de Janeiro: MEDSI; 2003. p. 163-73.

61. Costa MMB. Proteção de vias aéreas. In: Deglutição \& disfagia- Bases morfofuncionais e videofluoroscópicas. Rio de Janeiro: Medbook; 2013. p. 38-45.

62. Costa MMB, Silva RI, Lemme EM, Tanabe R. Apneia de deglutição no homem adulto. Gastroenterology. 1998;35:32-9.

63. Costa MMB, Lemme EM. Coordination of respiration and swallowing: functional pattern and relevance of vocal folds closure. Arq Gastroenterol. 2010;47:42-8

64. Costa MMB, Maliska C. A New Hypothesis for Fluidification of Vocal-Fold Mucus: Scintigraphic Study. J Voice. 2012;26:276-9.

65. Costa MMB, Moscovi M, Koch HA, Pereira AA. Avaliação videofluoroscópica da transição faringe-esofágica e esfincter esofágico superior. Radiol Bras. 1992;25:11-8.

66. Dantas RO, Dodds WJ, Massey BT, Kern MK. The effect of high- vs low-density barium preparations on the quantitative features of swallowings. Am J Roentgenol. 1989;153:1191-5

67. Pommerenke WT. A study of the sensory areas eliciting the swallowing reflex. Am J Physiol. 1928;84:36-41.

68. Fujiu M, Toleikis JR, Logemann JA, Larson CR. Glossopharyngeal evoked potentials in normal subjects following mechanical stimulation of the anterior faucial pillar. Electroenceph Clin Neurophysiol. 1994;92:183-95.

69. Alvite MFL, Lopes RLC, Costa MMB. Estimulação mecânico-térmica dos pilares palatoglosso. Arq Gastroenterol. 2007;44:221-6.

70. Costa MMB. Fase faríngea da deglutição. In: Deglutição \& disfagia- Bases morfofuncionais e videofluoroscópicas. 2013. p. 91-112.

71. Costa MMB. Dinâmica esfincteriana. In: Deglutição \& disfagia- Bases morfofuncionais e videofluoroscópicas. Rio de Janeiro: Medbook; 2013. p. 133-47.

72. Lockhart RD, Hamilton GF, Fyfe FW. Anatomy of the human body. Philadelphia: Lippincott; 1960.

73. Costa MMB. Fase esofágica da deglutição. In: Deglutição \& disfagia- Bases morfofuncionais e videofluoroscópicas. Rio de Janeiro: Medbook; 2013. p. 163-78.

74. Costa MMB. Esôfago: anatomia médico-aplicada. In: Esôfago. Rio de Janeiro: Ed Rubio; 2005. p. 1-12.

75. Rhoades RA, Pflanzer RG. Muscle. In: Human Physiology. 3ed ed. Orlando; 1996. p. 466-507.

76. Costa MMB. Bases biofísico-químicas aplicáveis a dinâmica da deglutição. In: Deglutição \& disfagia- Bases morfofuncionais e videofluoroscópicas. Rio de Janeiro: Medbook; 2013. p. 1-26.

77. Berne RM, Levy MN. Gastrointestinal motility. In: Physiology. 4ed ed. St. Louis: Mosby; 1998. p. 589-616. 